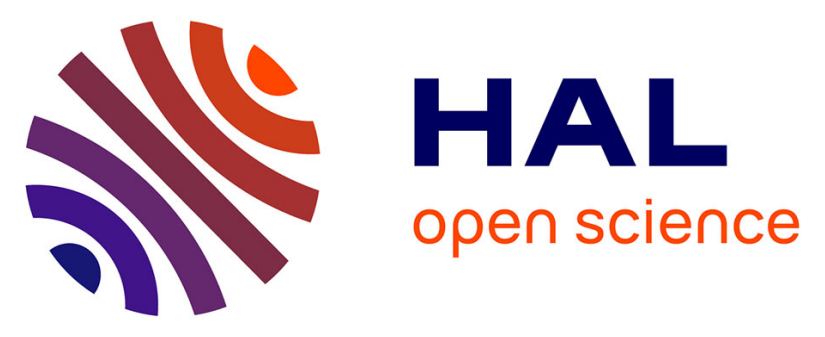

\title{
Coupled hydrogeophysical inversion of DNAPL source zone architecture and permeability field in a 3D heterogeneous sandbox by assimilation time-lapse cross-borehole electrical resistivity data via ensemble Kalman filtering
}

Xueyuan Kang, Xiaoqing Shi, Yaping Deng, André Revil, Hongxia Xu, Jichun $\mathrm{Wu}$

\section{- To cite this version:}

Xueyuan Kang, Xiaoqing Shi, Yaping Deng, André Revil, Hongxia Xu, et al.. Coupled hydrogeophysical inversion of DNAPL source zone architecture and permeability field in a 3D heterogeneous sandbox by assimilation time-lapse cross-borehole electrical resistivity data via ensemble Kalman filtering. Journal of Hydrology, 2018, 567, pp.149-164. 10.1016/j.jhydrol.2018.10.019 . hal-02324224

HAL Id: hal-02324224

https://hal.science/hal-02324224

Submitted on 23 Nov 2020

HAL is a multi-disciplinary open access archive for the deposit and dissemination of scientific research documents, whether they are published or not. The documents may come from teaching and research institutions in France or abroad, or from public or private research centers.
L'archive ouverte pluridisciplinaire HAL, est destinée au dépôt et à la diffusion de documents scientifiques de niveau recherche, publiés ou non, émanant des établissements d'enseignement et de recherche français ou étrangers, des laboratoires publics ou privés. 
Research papers

\title{
Coupled hydrogeophysical inversion of DNAPL source zone architecture and permeability field in a 3D heterogeneous sandbox by assimilation time-lapse cross-borehole electrical resistivity data via ensemble Kalman filtering
}

\author{
Xueyuan Kang ${ }^{\mathrm{a}}$, Xiaoqing Shi ${ }^{\mathrm{a}, *}$, Yaping Deng ${ }^{\mathrm{a}}$, André Revil ${ }^{\mathrm{b}}$, Hongxia Xu ${ }^{\mathrm{a}}$, Jichun Wu ${ }^{\mathrm{a}, *}$ \\ ${ }^{a}$ Key Laboratory of Surficial Geochemistry of Ministry of Education, School of Earth Sciences and Engineering, Nanjing University, Nanjing 210023, China \\ ${ }^{\mathrm{b}}$ Univ. Grenoble Alpes, Univ. Savoie Mont Blanc, CNRS, IRD, IFSTTAR, ISTerre, 38000 Grenoble, France
}

\section{A R T I C L E I N F O}

\section{Keywords:}

Dense non-aqueous phase liquids

Electrical resistivity tomography

Joint inversion

Subsurface heterogeneity

Containment source architecture

\begin{abstract}
A B S T R A C T
Characterization of dense non-aqueous phase liquid (DNAPL) distribution is important to facilitate the decision of remediation strategies. However, it is still a great challenge to characterize DNAPL source zone architecture with high resolution due to subsurface heterogeneity and relatively sparse data from traditional hydrogeological investigations. To overcome difficulties from such sparse data, electrical resistivity tomography (ERT) is introduced to locate DNAPL using time-lapse cross-borehole measurements. Due to the significant impact of geological heterogeneity on DNAPL source zone architecture, a data assimilation framework based on the coupled multiphase fluids-ERT model is developed to jointly invert DNAPL saturation and the permeability field using time-lapse ERT data. To validate the efficiency and performance of this framework, synthetic and laboratory experiments are both performed to monitor DNAPL migration and distribution in 3D heterogeneous sandbox with cross-borehole ERT. Result shows that time-lapse ERT and direct inversion can map the evolution of the DNAPL plume but loses details regarding the plume morphology due to the over-smoothing caused by geophysical inversion using an isotropic and homogeneous roughness-based regularization procedure. By contrast, the coupled inversion is successful to characterize both the permeability field and the evolution of the DNAPL plume with a higher resolution. This is because the coupled inversion is able to directly translate raw geophysical data into hydrologic meaningful information and therefore avoid artifacts caused by direct geophysical inversion.
\end{abstract}

\section{Introduction}

Dense non-aqueous phase liquid (DNAPL) are prevalent at a large number of industrialized sites and brownfields throughout the world (National Research Council, 2005, 2013; Newell et al., 2014). The variable release history and heterogeneity in the rock texture (affecting both permeability, capillary pressure, and wettability) make the spatial distribution of DNAPL in the source zone difficult to predict. After being released in the environment, DNAPL migrates through the water table under the influence of gravity and seep into the bottom unconfined aquifers (Soga, 2004; Orlando and Renzi, 2015). During the migration, a fraction of the DNAPL remains trapped within the pores as discontinuous ganglia, while others may be retained above horizons characterized by locally low-permeabilities (e.g., clay lenses) resulting in DNAPL pools (Lenhard et al., 1989; Timothy and Linda, 2000). In addition, the wettability of DNAPL might change (from non-wetting to wetting) due to the surfactants produced by the activity of microorganism (Ron and Rosenberg, 2001), which may make DNAPL spread into smaller pores and in the form of thin films (Dwarakanath et al., 2002). These cause difficulties in cleanup and can contribute to longterm groundwater contamination for decades to centuries. Although lots of research about DNAPL source zone were well reported, it presents a daunting environmental challenge to date.

Characterization of DNAPL source zone in sufficient detail is critical for long-term monitoring and management decisions for efficient remediation schemes (Koch and Nowak, 2015, 2016; Zheng et al., 2015). However, DNAPL migration is an unstable process, which is highly sensitive to subsurface heterogeneity, even tiny changes in porous medium might result in significantly different migration patterns and source zone architecture (Ferrari et al., 2015). Spatial structure of hydrogeological variables controlling DNAPL distribution, migration, and accumulation is often on centimeter scale. Remediation involving

\footnotetext{
* Corresponding authors.

E-mail addresses: shixq@nju.edu.cn (X. Shi), jcwu@nju.edu.cn (J. Wu).
} 
injection/extraction of the DNAPL containment are controlled by the same variables at the same scales. Thus, it is important to jointly characterize the DNAPL source zone architecture and the spatial structure of hydrogeological parameters (such as permeability and capillary pressure) with high resolution (Morrissey and Grismer, 1999; Kueper et al., 2014).

Compared with traditional investigation methods (e.g., intrusive drilling and sampling method), non-invasive geophysical methods (especially electrical resistivity tomography, ERT) have already been applied to the monitoring of DNAPL-contaminated sites. This is due to the low-cost and high sampling density of these non-intrusive method in characterizing the morphology of contaminant plumes (Chambers et al., 2010; Naudet et al., 2014; Steelman et al., 2017). Despite these advances, challenges still exist for practical ERT applications. The first challenge is related to the limited resolution of ERT by comparison with the complexity of DNAPL plume structures. The geological heterogeneities (e.g., local variations in the clay content) might produce resistivity anomalies, which disturb those caused by the presence of the DNAPL. With the development of time-lapse measurements, ERT shows its potential in detecting the migration of the DNAPL at heterogeneous structures (Chambers et al., 2004; Power et al., 2014; Orlando and Renzi, 2015; Deng et al., 2017). 4D inversion can be used to offset the heterogeneity of the background since only the resistivity changes are imaged (Karaoulis et al., 2011b). The second challenge is that, the commonly performed ERT survey from the top surface/ground suffers from a limited detection depth and low vertical resolution (Chambers et al., 2010). Thus, cross-borehole ERT can be used to solve this problem at DNAPL-contaminated sites in order to achieve higher vertical resolutions (Goes and Meekes, 2004; Chambers et al., 2010; Johnson et al., 2010).

With the time-lapse cross-borehole ERT data sets, two strategies can be used for instance to invert ERT data into relevant hydrology information. These strategies correspond to least square difference inversion approach and coupled hydrogeophysical inversion in which further a priori hydrogeological information is used in the inverse problem. In the first set of approaches, ERT apparent resistivity data are first converted to resistivity distribution through a least-square deterministic geophysical inversion method where a cost function is minimized (LaBrecque and Yang, 2001). This cost function is composed of a data misfit term and a regularization term where a priori information regarding the resistivity distribution is used (e.g., geostatistical structures, isotropic or anisotropic smoothness, image guided inversion, e.g., Zhou et al., 2014). Then, the obtained resistivity is mapped to hydrological properties (i.e., DNAPL saturation) using appropriate petrophysical relationships (e.g., Archie, 1942; Waxman and Smits, 1968; Revil et al., 2012). This approach is widely used, due to its simplicity (Power et al., 2014). However, in its cruder expression (regularization by isotropic smoothing) it has a limited application to invert time-lapse changes in DNAPL saturations because the smoothing may result in loss of resolution and it is not necessarily realistic in this case in producing physically meaningful resistivity distributions (Karaoulis et al., 2011a).

In the present study, to overcome the issues discussed above with traditional least-square inversion technique, we developed a data assimilation framework based on the coupled multiphase fluids-ERT model. This approach enables to estimate both the subsurface heterogeneity and DNAPL distribution through sequentially incorporating the time-lapse apparent resistivity measurements. Previous works (Hinnell et al., 2010; Irving and Singha, 2010; Mboh et al., 2012; Pollock and Cirpka, 2012; Tran et al., 2014; Camporese et al., 2015) have developed coupled hydrogeophysical inversion scheme to incorporate the underlying physics of the monitored process into the inversion of the geophysical data. For instance, Hinnell et al. (2010) and Mboh et al. (2012) investigated how coupled hydrogeophysical approach could improve soil hydraulic property estimation. Hinnell et al. (2010) developed a synthetic infiltration test monitored by the surface-based ERT and the result showed that petrophysical coupling can reduce parameter errors, but only if the underlying hydraulic model is a faithful representation of the hydrologic processes. Mboh et al. (2012) also improved the precision of parameter estimation from the fusion of inflow measurements with ERT data. Pollock and Cirpka (2012) performed a real-world laboratory salt tracer experiment with ERT and hydraulic head measurements. They recovered the detailed permeability structure using the mean arrival times of electrical potential perturbations and hydraulic head measurements. The coupled scheme can be based on either deterministic inversion approaches or stochastic ones (e.g., Jardani et al., 2013). Among the existing strategies, the EnKF (Ensemble Kalman Filter), which uses an ensemble of realizations to approximate the statistics of state variables (Evensen, 2009), have been proved to be an effective assimilating information approach to merge hydrogeological and geophysical information (Camporese et al., 2015). However, the application of coupled inversion on real-world DNAPL migration experiments has never been reported to date.

The outline of the paper is as follows. In Section 2, we introduce the DNAPL sandbox experiment monitored by boreholes equipped with electrodes used to acquire time-lapse ERT data. Then, we develop a data assimilation framework based on coupled hydrogeophysical inversion of ERT and multiphase flow. To test the performance of the proposed framework, we conduct two cases (synthetic and laboratory experiments in Sections 3 and 4, respectively) in two different situations of the real-world sites (the complex heterogeneity and the layer heterogeneity), respectively. A quantitative comparison between the classical geophysical approach and the coupled hydrogeophysical inversion scheme is also discussed in these sections.
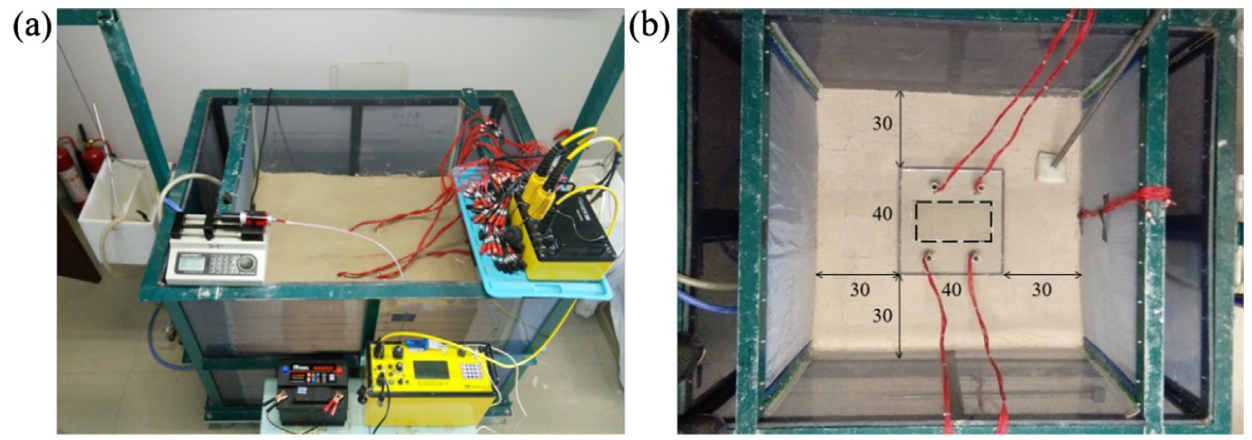

Fig. 1. (a) Photo of the experimental apparatus. (b) Overhead photo of the packing process. The unit is centimeter ( $\mathrm{cm}$ ). The black dotted box represents the center domain which is monitored by ERT. 
(a)

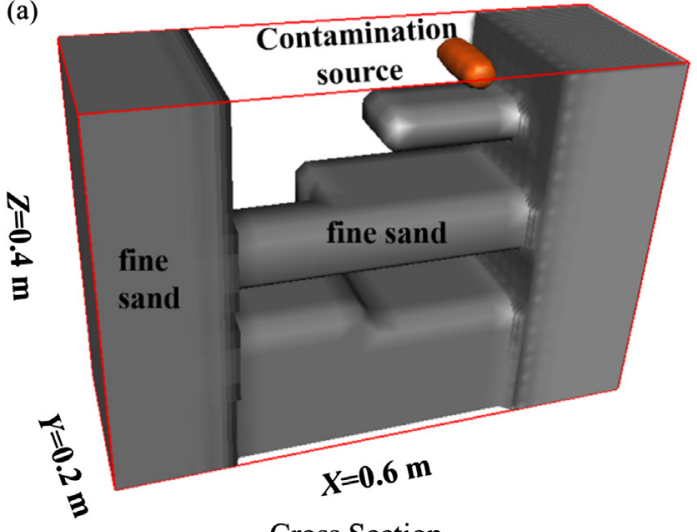

(c)

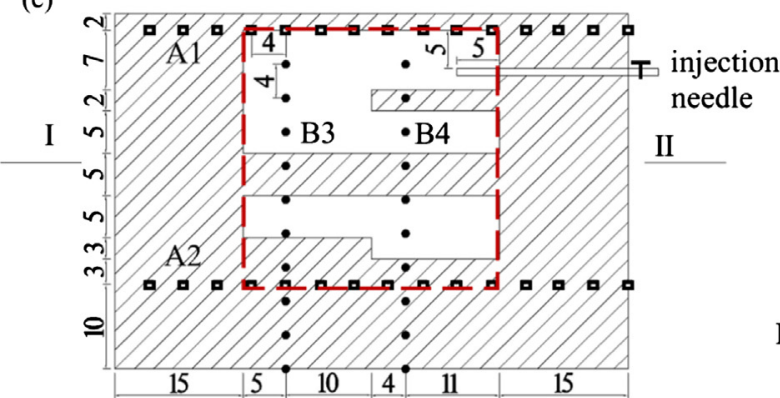

1

(b)

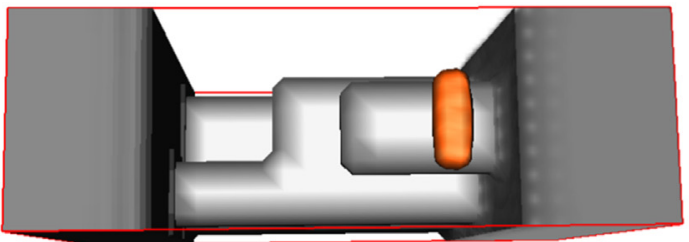

(d)

Plan View

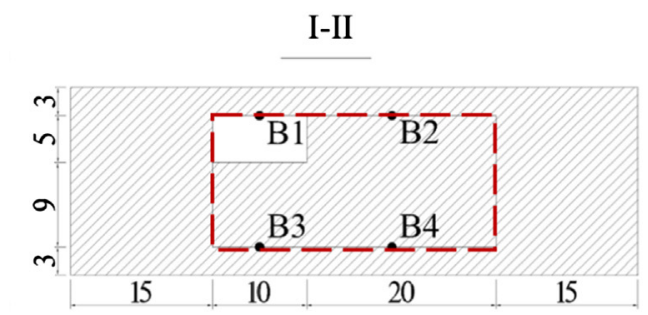

Legend

एA fine sand $\quad$ vertical boreholes electrodes

coarse sand $\square$ horizontal boreholes electrodes

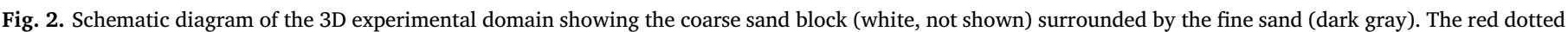

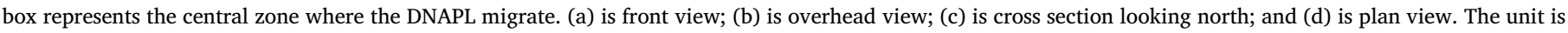

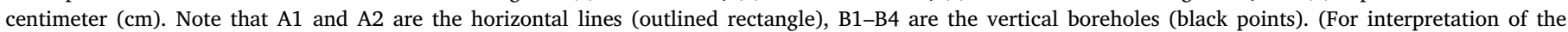
references to color in this figure legend, the reader is referred to the web version of this article.)

\section{Methodology}

\subsection{DNAPL sandbox experiment monitored by time-lapse cross-borehole} ERT

\subsubsection{Sandbox setup}

The experiment was performed in a $3 \mathrm{D}$ plexiglass sandbox $(1 \mathrm{~m} \times 1 \mathrm{~m} \times 1 \mathrm{~m})$ (Fig. 1a). Only the inner volume of the sandbox is investigated by ERT (i.e., $0.6 \mathrm{~m}$ and $0.2 \mathrm{~m}$ in the $x$ and $y$ dimensions, respectively, and $0.4 \mathrm{~m}$ in the vertical dimension and located in the center of the sandbox), in order to minimize the impact of the boundary conditions. The distance between the central domain and the boundary are close to similar 3D sandbox experiments (Seferou et al., 2013; Power et al., 2014, 2015), where the boundary effect can be safely neglected.

The DNAPL was injected into the sandbox through a horizontal injection pipe corresponding to the "contamination source" in Fig. 2a and $\mathrm{b}$. This pipe corresponds to a $2 \mathrm{~mm}$-diameter PTFE tube in which 5 holes ( $1 \mathrm{~mm}$ in diameter) were made for the injection. In this work, we used hydrofluoroether (HFE-7100) to mimic the behavior of the DNAPL (Orlando and Renzi, 2015), properties specified in Table 1. Due to the high resistivity of fresh DNAPL, it is thus feasible for the application of the ERT detection (Lucius et al., 1992; Johansson et al., 2015). Note that, however, the presence of biofilm and biodegradation in NAPLs sites may change the observed resistivity of these plumes from being resistive to conductive (Atekwana and Atekwana, 2010; Atekwana and Abdel Aal, 2015). Even if the plumes were considered more conductive than background groundwater, this would enhance the contrast with the resistive DNAPL source zone and the ERT method is still useful in characterizing the DNAPL source zone (Power et al., 2013).

Prior to filling the sandbox, a total of 70 stainless steel electrodes
Table 1

Fluids properties used in this study.

\begin{tabular}{llll}
\hline Properties & HFE-7100 & TCE & Electrolyte $^{\mathrm{a}}$ \\
\hline Relative density $\left(\mathrm{g} / \mathrm{cm}^{3}\right)$ & 1.5 & 1.464 & 1 \\
Relative viscosity $(\mathrm{cP})$ & 0.6 & 0.59 & 1 \\
Surface tension $(\mathrm{mN} / \mathrm{m})$ & 13.6 & 29.3 & 71.75 \\
Water solubility $(\mathrm{mg} / \mathrm{L})$ & 12 & 1100 & - \\
Resistivity $(\Omega \cdot \mathrm{m})$ & $10^{6 \mathrm{~b}}$ & $10^{6 \mathrm{c}}$ & $4.4^{\mathrm{d}}$ \\
\hline
\end{tabular}

a The electrolyte consists of a $0.013 \mathrm{~mol} / \mathrm{L}$ solution of $\mathrm{NaCl}$.

b Orlando and Renzi (2015).

c Olhoeft (1992).

d Measured data.

were installed inside the sandbox in six linear arrays (two horizontal lines and four vertical boreholes, shown in Fig. 2c and d). The electrodes $(2.5 \mathrm{~mm}$ in diameter, $10 \mathrm{~mm}$ in length and only inserted $6 \mathrm{~mm}$ into the porous media) were fixed to PTFE tubes ( $15 \mathrm{~mm}$ in diameter). They were placed $4 \mathrm{~cm}$ apart both in vertical boreholes and horizontal lines. The distance between the vertical boreholes was $14 \mathrm{~cm}$ (Fig. 2c and d). For the horizontal lines, the vertical distance between surface and tunnel arrays was $30 \mathrm{~cm}$, which was conform to the optimum distance suggested by Simyrdanis et al. (2015). The resistivity measurements were collected with an eight-channels geo-resistivity meter (SuperSting R8, Advanced Geoscience Inc). The electrode configuration used here was bipole-bipole, which was a commonly used array in cross-borehole measurement (Slater et al., 2002; Seferou et al., 2013). Cross-borehole measurements were collected along certain combinations between boreholes (A1-A2, B1-B3, B2-B4, in Fig. 2c and d), in order to reduce the total measuring time.

The porous media used in the sandbox was Accusand silica sands (20/30, 70/100 mesh) obtained from Unimin Corporation (USA), which 
Table 2

Properties of the porous media used in the experiment.

\begin{tabular}{lll}
\hline Sands & $20-30$ mesh & $70-100$ mesh \\
\hline Mean grain size $(\mathrm{mm})$ & 0.73 & 0.17 \\
Density $\left(\mathrm{g} / \mathrm{cm}^{3}\right)$ & 2.56 & 2.56 \\
Permeability $\left(10^{-10} \mathrm{~m}^{2}\right)$ & 3.02 & 0.27 \\
Porosity & 0.35 & 0.37 \\
\hline
\end{tabular}

has been used in similar sandbox experiments (Petri et al., 2015). With these sands, a heterogeneous structure was constructed as explained below. The 70/100 and 20/30 mesh size sands (fine and coarse sand in Fig. 2a) were used as low-permeability and high-permeability media, respectively, in order to make DNAPL flow bypass and accumulate around the fine sand layers. The properties of the sands are provided in Table 2.

The sandbox was firstly packed with fine sand (70-100 mesh) in lifts of $5 \mathrm{~cm}$ to an elevation of $0.70 \mathrm{~m}(0.30 \mathrm{~m}$ depth from the surface) to provide a homogeneous background. At this elevation, the bottom horizontal line and electrodes (i.e., A2 in Fig. 2c) were set at designed location and carefully filled with fine sand. Then the layered lenses in the inner volume (Fig. 2a), were accurately packed by four rectangular aluminum frames, which was constructed the size of each lens, after that the frame was removed. At the surface, the surface horizontal line and electrodes (i.e., A1 in Fig. 2c) were installed. In addition, at the top of the surface horizontal line, a fine grain sand layer (using 100/ 140 mesh size sands, mean grain size is $0.12 \mathrm{~mm}$ ) with a thickness of $2 \mathrm{~cm}$ was set to avoid possible escaping from backflow of DNAPL. After the packing of sandbox, the dry sand was saturated with slow injection of electrolyte ( $363 \mathrm{~L}$, approximately 1 pore volume) from the base of the sandbox over 2 days, then stood the sandbox for a week to ensure the sand was entirely filled with electrolyte. The electrolyte consisted of a $0.013 \mathrm{~mol} / \mathrm{L}$ solution of $\mathrm{NaCl}$ with a resistivity of $4.4 \Omega \mathrm{m}$ at $20^{\circ} \mathrm{C}$. Noted that the pore fluid used here is quite conductive $(4.4 \Omega \mathrm{m})$, it is because the resistivity of the pore fluid in organic contaminant fields is often lower than $10 \Omega \mathrm{m}$. For instance, Steelman et al. (2017) reported the resistivity of the groundwater in a DNAPL contaminant field ranges from 1.6 to $10.0 \Omega \mathrm{m}$. Revil et al. (2013) reported the resistivity of the pore fluid in former S-3 ponds contaminant field ranged from 1.0 to $12.5 \Omega \mathrm{m}$.

\subsubsection{Experimental procedure}

Prior to the injection of the DNAPL, the initial state (background) was recorded by the resistivity meter three times to characterize the static saturated water conductivity conditions. The average relative error calculated from these three duplicate measurements is $3 \%$. Later, the background measurement (the average of these three measurements) was used to produce differential time-lapse images from subsequent surveys. During this experiment, a total volume of $1000 \mathrm{ml}$ of DNAPL (HFE-7100) was injected into the sandbox with a constant rate of $0.5 \mathrm{ml} / \mathrm{min}$ through the injection pipe using a Harvard Apparatus syringe pump and glass syringe (Sigma-Aldrich Corp., St. Louis, Missouri, USA). To monitor continuous movement of DNAPL, the injection was maintained during ERT measurement. The ERT data was collected every $100 \mathrm{~min}$ until the injection was over $(t=2000 \mathrm{~min})$. An additional survey was taken at $t=7000 \mathrm{~min}$, in order to investigate the redistribution of DNAPL after injection finished. The acquisition time for each survey was $16 \mathrm{~min}$. During that time, the DNAPL injection volume is only $8 \mathrm{ml}$ (the injection rate is $0.5 \mathrm{ml} / \mathrm{min}$ ). By contrast, the total time for DNAPL injection is $2000 \mathrm{~min}$ (the total volume is $1000 \mathrm{ml}$ ). Therefore, the NAPL movement can be approximately neglected during the short times required for ERT data acquisition. For each survey, a total of 1894 apparent resistivity measurements were recorded. For each measurement, a $10 \mathrm{~mA}$ current was injected into the sand and a $0.2 \mathrm{~s}$ of the measuring time was chosen to decrease the total acquisition time. In order to calculate the stacking error for each data, three stacks were used.

\subsection{Direct difference inversion for estimating the DNAPL saturation}

\subsubsection{Electrical resistivity tomography}

The electrical resistivity tomography (ERT) is a geophysical method which can reconstruct the subsurface resistivity from the injected current $I$ and measured voltage $V$ (and thus the apparent resistivity $\rho_{a}$ ). ERT consists of the forward model and inversion method.

1. The ERT forward model can predict apparent resistivity value, given the space-time distribution of bulk electrical conductivity, by solving the partial differential equation:

$\nabla \cdot\left(\frac{1}{\rho} \nabla V\right)=-I \delta(\mathbf{r})$

where $\rho$ is the spatial distribution of resistivity in the media, $\Omega \cdot \mathrm{m} . V$ is the electric potential value, V. $\delta$ is the Dirac delta function, at a point $\mathbf{r}$ represents a single current electrode, idealized as a point source at the origin with strength $I$ (A).

2. Through the inversion method, the subsurface resistivity is reconstructed from the apparent resistivities (or resistances). The classical inversion approach is often considered as a regularized optimization problem, where the objective function to be minimized can be expressed as a weighted sum of data misfit and a regularization term. The objective function can be shown as (Binley and Kemna, 2005):

$\psi(\mathbf{m})=\mathbf{W}_{d}\|[\mathbf{d}-\mathbf{f}(\mathbf{m})]\|^{2}+\alpha \mathbf{W}_{m}\left\|\left(\mathbf{m}-\mathbf{m}_{r e f}\right)\right\|^{2}$

where $\mathbf{W}_{d}\|[\mathbf{d}-\mathbf{f}(\mathbf{m})]\|^{2}$ denotes a L2-norm-based measure of the data misfit, $\mathbf{W}_{m}\left\|\left(\mathbf{m}-\mathbf{m}_{\text {ref }}\right)\right\|^{2}$ is a stabilizing model objective function, and $\mathbf{m}$ and $\mathbf{m}_{r e f}$ are the vector of estimated and reference resistivity, respectively. $\mathbf{d}$ is the vector of measured apparent resistivity data. $\mathbf{f}(\mathbf{m})$ is the vector of resistivity predicted by the forward model. $\mathbf{W}_{d}$ and $\mathbf{W}_{m}$ are data and model weighting matrixes, respectively. And $\alpha$ is a regularization parameter.

To better characterize resistivity anomaly caused by DNAPL infiltration and get a faster convergence, the sequential inversion method is used here. It assumes the inverted background data as background resistivity model (i.e., the reference model $\mathbf{m}_{\text {ref }}$ in Eq. (2)) and inverts for the differences between the background and time-lapse data sets (LaBrecque and Yang, 2001).

In this study, both the forward and sequential difference inversion problems are solved by AGI EarthImager 3D software (AGI, 2010), which employs the finite difference method for forward modeling and both root-mean-squared (RMS) error and L2-norm defined as the sum of the squared weighted data errors to evaluate how good the fit is during the inversion progress. For geophysical forward and inversion modeling, we use the "Sand Box boundary condition" (no flow boundary condition) module in AGI EarthImager 3D to simulate the boundary effect caused by the insulating cuboid sandbox (AGI, 2010).

\subsubsection{Estimation of DNAPL saturation and volume}

With the inverted resistivity distribution, the distribution of DNAPL saturation can be estimated through an appropriate petrophysical relationship, which is used to connect the geophysical and hydrogeological properties of the porous material. A partially saturated porous material is usually a three-phase composite consisting of a solid phase, a gas phase and a liquid phase (the electrolyte). The solid phase (silica sand) is insulating. In this case, the electrical conductivity of the porous material consists of a bulk conductivity term and a surface conductivity term which occurs along the pore-water/mineral interface in the so-called electrical double layer (Revil et al., 2012). For clean sands which is clay-free, the surface conductivity is so small that can be safely neglected (Waxman and Smits, 1968; Gelius and Wang, 2008). 
Therefore, we can use the second Archie equation (Archie, 1942) to describe the saturation of DNAPL, $S_{N}$ (ERT-based NAPL saturation), which leads to

$S_{N}=1-\left(\frac{\rho_{0}}{\rho_{t}}\right)^{1 / n}$

where $\rho_{0}$ is the initial resistivity of the water-saturated sand (background resistivity), $\rho_{t}$ is the ERT measured resistivity of partially saturated medium after the DNAPL infiltration, $n$ is saturation exponent, appears to be close to $n=2.0$ for clean sand (clay-free) (Archie, 1942; Hölz et al., 2015; Liang et al., 2016; Deng et al., 2017). Due to its simplicity, classical relationships such as Archie equation are still popular in the estimation of oil saturation (Chambers et al., 2004; Power et al., 2014).

With the distribution of DNAPL saturation calculated through Archie equation, the total DNAPL volumes $V_{N}$ can be estimated by:

$V_{N}=\sum_{i=1}^{n x} \sum_{j=1}^{n y} \sum_{k=1}^{n z}\left(S_{N, i, j, k} \phi \cdot \Delta x \Delta y \Delta z\right)$

where $n x, n y, n z$ are the number of the grids in $x, y$ and $z$ directions; $S_{N, i, j, k}$ is the estimated DNAPL saturation for certain grid; $\phi$ is the porosity; $\Delta x, \Delta y$ and $\Delta z$ are the length of the grids in $x, y$ and $z$ directions.

\subsection{Coupled hydrogeophysical inversion}

\subsubsection{Coupled multiphase fluids model and forward ERT model}

To simulate the resistivity anomaly caused by the presence of DNAPL contaminant, a coupled model is developed between the multiphase fluids model, effective medium resistivity model (petrophysical relationship) and geophysical forward model.

The problem of nonreactive DNAPL infiltration and transportation in 3D heterogeneous field is solved here via the T2VOC software (Falta et al., 1995). T2VOC is a numerical simulator for three-phase, threecomponent, non-isothermal flow of water, air, and a volatile organic compound (VOC) in multidimensional heterogeneous porous media. T2VOC uses a general integral finite difference formulation for multiphase, multicomponent mass and energy balance equations known as MULKOM (Pruess, 1983). The model has been used for numerous studies of NAPL migration and remediation at the field scale, including in 3D, heterogeneous domains (e.g., Rasmusson and Rasmusson (2009)). In this work, with the initial distribution of $S_{N}$ (DNAPL saturation) and $k$ (absolute permeability), we can obtain the real-time distribution of $S_{N}$ through T2VOC simulator.

Using an appropriate petrophysical relationship, the hydrological state (e.g., $S_{N}$ ) can be transformed into the electrical properties (e.g., $\rho$, resistivity). Here again, in absence of clay particles, we can use Archie law as the appropriate physical law connecting the saturation to resistivity. In presence of clay-rich materials, such a relationship may lead to errors (Patnode and Wyllie, 1950). To overcome this weakness, an effective medium algorithm (Berg, 2007) is used to combine sand, shale, and hydrocarbon components into the Hanai-Bruggeman equation (Hanai, 1960):

$\phi S_{w}=\left(\frac{\rho_{w}}{\rho_{t}}\right)^{\frac{1}{m}} \cdot\left(\frac{\rho_{t}-\rho_{r}}{\rho_{w}-\rho_{r}}\right)$

where $\phi$ is porosity, $S_{w}$ is water phase saturation (in water-NAPL two phase system, $S_{w}=1-S_{N}, S_{N}$ is NAPL phase saturation), $\rho_{w}$ is water resistivity (continuous phase), $\rho_{t}$ is total resistivity of all components, $m$ is the cementation exponent (the same as used in Archie's law), $\rho_{r}$ is the resistivity of disperse phase (e.g., the rock and hydrocarbon particles).

Using discrete integration of Eq. (5), the effective medium algorithm adds tiny, but proportional, amounts of disperse elements into the disperse component, including clay, sand, and hydrocarbons (Berg, 2007). The mixture resistivity from the current iteration will be the prior fluid resistivity for the next iteration. We only consider the simple condition (clean sand) in this work, where the Archie's equation might be sufficient enough. However, to make it convenient for future applications in clayey soils, the effective medium algorithm by Berg (2007) was used in this work, which can work well in both clay-free sand and conductive matrix (clay-rich materials) (Berg, 2007; Power et al., 2013).

With the electrical properties (e.g., $\rho$, resistivity) converted from petrophysical relationships, the raw geophysical data (apparent resistivity) is obtained through the geophysical forward model as mentioned in Section 2.2.1.

\subsubsection{Ensemble Kalman filter}

In this work, the EnKF (Ensemble Kalman Filter) is used as an inversion tool to jointly estimate the distribution of DNAPL saturation and aquifer heterogeneous parameter field ( $Y, \log _{10^{-}}$permeability). The EnKF (Evensen, 2009) is a sequential Monte Carlo method based on the Bayes' theorem. It uses an ensemble of realizations to estimate the statistics of model parameters (e.g., permeability) and state variables (e.g., DNAPL saturation), with the assumptions that the forward model is a first-order Markov process and measurement errors are independent from time to time.

At the initial time $t_{0}, N_{r}$ realizations of $Y\left(\log _{10^{-}}\right.$permeability) field are produced with a prior guess of the geostatistical parameters: mean, variance and correlation length of $Y$ field. The augmented state vector can be defined as:

$\mathbf{y}_{t}=\left[\mathbf{p}_{t}, \mathbf{s}_{t}\right]^{T}$

where $\mathbf{p}_{t}$ is the state parameter vector (e.g., $Y, \log _{10^{-}}$permeability) at time $t$, while $\mathbf{s}_{t}$ is the state variable vector (e.g., $S_{N}$, DNAPL saturation). $N_{y}$ is the dimension of $\mathrm{y}_{t}: N_{y}=N_{m}+N_{s}$, where $N_{s}$ is the grid number in the multiphase flow system and $N_{m}$ is the number of the parameter that need to be estimated.

Starting with the same $S_{N O}$ (the initial DNAPL saturation) for each $Y$ realization, the multiphase flow is propagated forward to the first measurement time $t_{1}$, using the multiphase fluids model. At time $t_{1}$, the augmented state vector $\mathbf{y}_{1}$ is updated through this formula:

$\mathbf{y}_{j, i}^{a}=\mathbf{y}_{j, i}^{f}+\mathbf{C}_{i}^{f} \mathbf{H}^{T}\left[\mathbf{H C}_{i}^{f} \mathbf{H}^{T}+\mathbf{C}_{D_{i}}\right]^{-1}\left(\mathbf{d}_{i}-\mathbf{H} \mathbf{y}_{j, i}^{f}\right)$

where $a$ refer to model analysis, while $f$ represents model forecast or initial guess, $\mathbf{y}_{j, i}^{f}$ is the estimated augmented state vector for realization $j$ at time $t_{i}$ based on information at $t_{\mathrm{i}-1}, \mathbf{y}_{j, i}^{a}$ is the updated augmented state vector at $t_{i}$ and $\mathbf{H}$ is the operator which maps model simulation results to actual measurements, $\mathbf{C}_{i}^{f}$ is the covariance matrix at time $t_{i}$, computed from the ensemble statistics, $\mathbf{C}_{D_{i}}$ is the error covariance matrix of the observations, $\mathbf{d}_{i}$ is the vector of observations at $t_{i}$.

Here, EnKF is applied recursively, a methodology known as the restart EnKF approach (Wen and Chen, 2005; Camporese et al., 2015). At first, the multiphase flow model is rerun from $t_{0}$ to $t_{i}$ when the new measurement data become available. Then the $Y$ ( $\log _{10}$ - permeability) values at each measurement time $t_{i}$ is updated through Eq. (7). The procedure is repeated until the end of assimilation. In this work, update of $S_{N}$ is not necessary. Because with the updated parameters filed, the distribution of DNAPL saturation can be obtained by rerunning the forward model.

\subsubsection{Data assimilation framework}

Fig. 3 shows the flowchart of the data assimilation framework. At first, an ensemble of $Y\left(\log _{10}\right.$ - permeability) fields is generated by the sequential Gaussian simulator in Geostatistical software library (GSLIB) (Deutsch and Journel, 1998). With the parameters fields, the multiphase fluids model is run to get the evolution of DNAPL saturation. Using an appropriate petrophysical relationship (effective medium algorithm), the distribution of resistivity is converted from DNAPL saturation. Through geophysical forward model, the resistivity is 


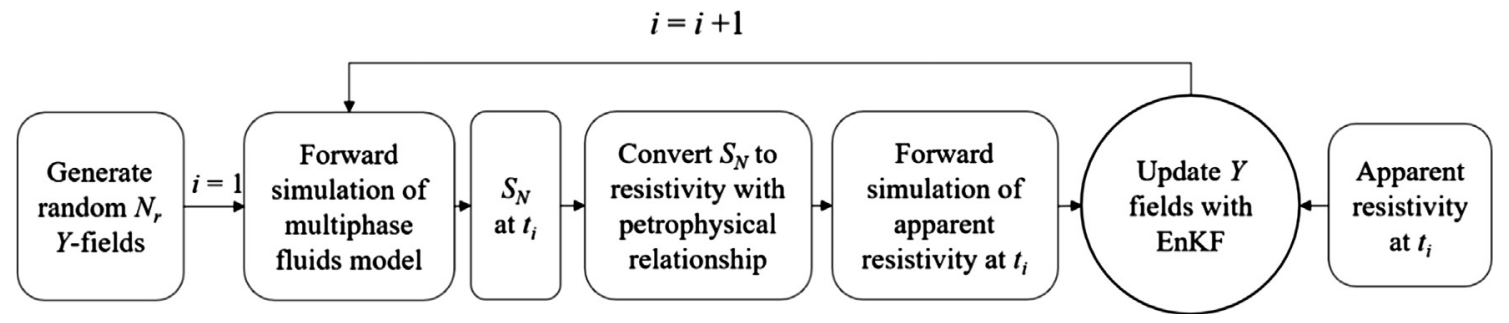

Fig. 3. Flowchart illustrating the data assimilation framework. Note that $S_{N}$ denotes the saturation of the DNAPL, $Y$ represents log- permeability.

transferred to the apparent resistivity data. Later, the EnKF is used to update parameters $\left(Y, \log _{10}\right.$-permeability) by assimilating the apparent resistivity measurements. The procedure is repeated until the end of assimilation.

\section{Synthetic case}

\subsection{Synthetic case set-up}

To compare with the laboratory $3 \mathrm{D}$ sandbox experiment, the synthetic case is based on the size of sandbox center domain (red dotted box in Fig. 2c and, $0.3 \mathrm{~m} \times 0.14 \mathrm{~m} \times 0.3 \mathrm{~m}$ ), which is discretized into $15 \times 7 \times 15=1575$ cuboid elements (Fig. 4). Pressure boundary condition is imposed $\left(P=1.01 \times 10^{5} \mathrm{~Pa}\right)$ at the top face of the center domain. In addition, fixed boundary conditions (the volumes of the boundary cells are so large $\left(1 \times 10^{5} \mathrm{~m}^{3}\right)$ that flow in and out boundary cells will have negligible effect on pressure in boundary cells) are set at four sides and the bottom of the center domain for the multiphase fluids model. The reference $Y$ field (representing the permeability field here) (Fig. 4a) is generated by sequential Gaussian simulator in GSLIB with mean $\langle Y\rangle=-9.55 \log _{10}\left(\mathrm{~m}^{2}\right)$, standard deviation $\sigma_{Y}=0.35 \log _{10}\left(\mathrm{~m}^{2}\right)$, correlation lengths $I_{x}=0.075 \mathrm{~m}$, $I_{y}=0.035 \mathrm{~m}, I_{z}=0.075 \mathrm{~m}$ and the exponential covariance function. Similarly, the initial realizations of the $Y$ are also generated by GSLIB (Table 3). The realization size is taken as 500 .

In the synthetic case, we assume that there are no contaminants at the initial stage $t_{0}=0 \mathrm{~min}$. The DNAPL is uniformly injected in a contaminant source zone (Fig. 4b) of dimensions $3.6 \times 10^{-4} \mathrm{~m}^{3}$ $(x=-0.1-0.08 \mathrm{~m}, y=-0.06-0.04 \mathrm{~m}, z=-0.06$ to $-0.04 \mathrm{~m})$ with a content rate of $5.625 \mathrm{ml} / \mathrm{min}$ until $t=200 \mathrm{~min}$. In this study, we focus on characterizing the DNAPL source zone architecture and therefore, assume that the source location is known as prior information. The DNAPL plume migration is simulated using the trichloroethylene (TCE)

(a)

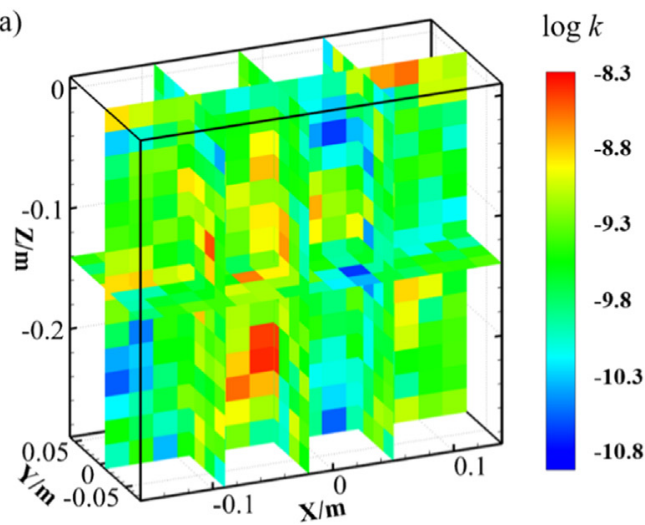

Table 3

Prior statistics of parameter field in numerical experiment.

\begin{tabular}{llllll}
\hline & $\langle Y\rangle$ & $\sigma_{Y}$ & $I_{x}$ & $I_{y}$ & $I_{z}$ \\
\hline Reference & -9.55 & 0.35 & 0.0375 & 0.0175 & 0.0375 \\
Numerical experiment & -9.21 & 0.35 & 0.0375 & 0.0175 & 0.0375 \\
\hline
\end{tabular}

Note that $\left\langle Y>\right.$ and $\sigma_{Y}$ are the mean and standard deviation of the $\log k$ (i.e., $\log _{10}$ permeability) field, respectively. $I_{x}, I_{y}, I_{z}$ represent the correlation lengths in $x, y$ and $z$ directions.

properties specified in Table 1, because it is a typical substance of organic contaminated sites (Rothmel et al., 1998; National Research Council, 2005). Parker's model (Parker and Lenhard, 1987) of $P_{c}-S$ and Stone's model (Stone, 1970) of $k_{r}-S$ are chosen to simulate DNAPL migration. Table 4 summarizes the model parameters employed for simulation. Because this work is focused on the estimation of heterogeneous permeability, other parameters (e.g., parameters of the petrophysical relationship and capillary pressure function) are assumed to be deterministic for the synthetic case.

The electrode array here (Fig. 4b) is the same as the sandbox experiment in Section 2. With the known electrode array and the reference $Y$ distribution, we can obtain the reference apparent resistivity data through the coupled multiphase fluids-ERT model. Adding Gaussian noise (relative error is $3 \%$ ) to the reference, the apparent resistivity measurement is acquired. The ERT measurement is acquired every $20 \mathrm{~min}$, from $t=20 \mathrm{~min}$ to $t=200 \mathrm{~min}$. Therefore, there are a total of ten ERT measurement vectors (each vector includes 1894 apparent resistivity data) available for the inversion.

\subsection{Direct difference inversion}

Through the geophysical inversion model in Section 2.2.1, the timelapse ERT data is transferred to dynamic resistivity distribution,

(b)

\section{Contamination}

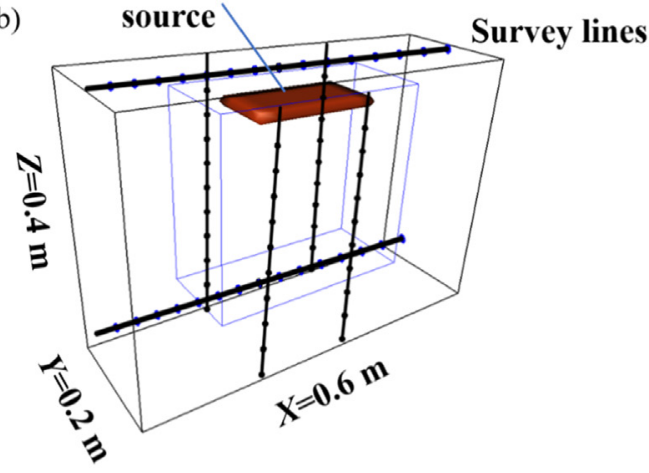

Fig. 4. The conceptual model of the synthetic experiment: (a) reference $\log _{10}$-permeability (log $k$ ) field; (b) sketch of the electrode arrays. The plain lines represent for the electrode arrays. The blue frame denotes the center domain used to simulate the migration of DNAPLs. The remaining volume of the tank is filled with a fine sand, which can hardly be infiltrated by the DNAPL. (For interpretation of the references to color in this figure legend, the reader is referred to the web version of this article.) 
Table 4

Model parameters for the synthetic case.

\begin{tabular}{lll}
\hline Parameter & Value & Comments \\
\hline Hydrogeological parameters & & \\
Sand porosity & $0.32^{\mathrm{a}}$ & Petrophysical relationship \\
Cementation exponent & $1.5^{\mathrm{b}}$ & $\begin{array}{l}\text { Petrophysical relationship } \\
\text { Sand resistivity }(\Omega \cdot \mathrm{m})\end{array}$ \\
TCE resistivity $(\Omega \cdot \mathrm{m})$ & $1000^{\mathrm{c}}$ & Petrophysical relationship \\
Water resistivity $(\Omega \cdot \mathrm{m})$ & $6.5^{\mathrm{a}}$ & Petrophysical relationship \\
Relative permeability function & & Petrophysical relationship \\
Water residual saturation $S_{w r}$ & $0.1^{\mathrm{e}}$ & \\
NAPL residual saturation $S_{n r}$ & $0.12^{\mathrm{e}}$ & $k_{r}-S$ formulation \\
Gas residual saturation $S_{g r}$ & 0 & $k_{r}-S$ formulation \\
Fitting coefficients $n^{\prime}$ & 3 & $k_{r}-S$ formulation \\
Capillary pressure function & & $k_{r}-S$ formulation \\
Residual liquid saturation $S_{l r}$ & $0^{\mathrm{f}}$ & \\
van Genuchten $n^{\prime \prime}$ & $1.84^{\mathrm{f}}$ & $P_{c}-S$ formulation \\
van Genuchten $\alpha_{g n}\left(\mathrm{~m}^{-1}\right)$ & $10^{\mathrm{f}}$ & $P_{c}-S$ formulation \\
van Genuchten $\alpha_{n w}\left(\mathrm{~m}^{-1}\right)$ & $11^{\mathrm{f}}$ & $P_{c}-S$ formulation \\
\hline
\end{tabular}

a Power et al. (2013).

b Berg (2007).

c Loke (2001).

d Olhoeft (1992).

e Schroth et al. (1996)

f Pruess and Battistelli (2002).

respectively. Based on the resistivity difference between the background and subsequent data sets, the DNAPL distribution is calculated from Eq. (3). Fig. 5a and b shows the estimated DNAPL distribution by traditional direct difference inversion. Compared with the reference (Fig. 5d and e), direct inversion can roughly reconstruct the distribution of DNAPL saturation. However, direct inversion result demonstrates that the DNAPL accumulates at the top (Fig. 5a and b), which are different from the reference distribution (Fig. $5 \mathrm{~d}$ and e). It is mainly because a cruder regularization by isotropic smoothing may result in loss of resolution and the isotropic smoothing is not realistic in this situation in producing physically meaningful resistivity and DNAPL distributions (see discussion in Karaoulis et al., 2011a). By producing a smoother result, this approach fails to accurately depict the fine architecture of the DNAPL plume.

\subsection{Coupled hydrogeophysical inversion}

Reference distribution, ensemble mean of the initial realizations and estimated distribution by coupled hydrogeophysical inversion for $Y$ $\left(\log _{10} k\right)$ and corresponded DNAPL saturation for synthetic case are shown in Fig. 5c-k. It demonstrates that the initial guess of the $Y$ fields (Fig. 5f) does not show any decent features. However, the $Y$ distribution estimated by coupled hydrogeophysical inversion (Fig. 5i) becomes very similar to the reference (Fig. 5c). Based on the $Y$ distribution, the DNAPL saturation distribution is calculated through multiphase fluids model. It is clear that the initial field (Fig. $5 \mathrm{~g}$ and $\mathrm{h}$ ) can't recover the reference distribution of $S_{N}$ (Fig. $5 \mathrm{~d}$ and e), while it is preferably reflected by coupled hydrogeophysical inversion (Fig. $5 \mathrm{j}$ and $\mathrm{k}$ ).

To quantitatively analyze the performance of the coupled hydrogeophysical inversion, the root mean square error (RMSE) is used as a criterion to demonstrate the agreement between the estimated and reference distribution of $Y$ and $S_{N}$ :

$\operatorname{RMSE}_{Y}=\sqrt{\frac{1}{N_{g}} \sum_{i=1}^{N_{g}}\left(Y_{t}-Y_{a}\right)^{2}}$

$\operatorname{RMSE}_{S}=\sqrt{\frac{1}{N_{g}} \sum_{i=1}^{N_{g}}\left(S_{t}-S_{a}\right)^{2}}$

where $N_{g}$ is the number of grids, $Y_{t}$ and $Y_{a}$ represent the reference and the estimated (ensemble mean) $Y$ ( $\log _{10}$-permeability) distribution. $S_{t}$ represents the reference $S_{N}$ distribution at $t=80$ and $120 \mathrm{~min}$, and $S_{a}$ stands for the estimated $S_{N}$ distribution computed by running the multiphase fluids model with the finally retrieved $Y$ distribution.

Another measure of the goodness of the results is the ensemble spread (ES), which represents the estimated uncertainty based on the ensembles:

$E S=\sqrt{\frac{1}{N_{g}} \sum_{i=1}^{N_{g}} \operatorname{VAR}\left(Y_{i}\right)}$

where $\operatorname{VAR}\left(Y_{i}\right)$ is the ensemble variance of the $\log k$ at each grid. If the EnKF estimates the uncertainty of the state properly, the ES should be close to the RMSE.

Temporal evolutions of RMSE between estimated and reference field are shown in Fig. 6a. It indicates the agreement between the ensemble mean and reference $Y$ distribution improves progressively as assimilation goes on. In addition, from the sixth to tenth step, the RMSE curses drop slower than former period. It demonstrates the measurement data from steady stages is less worthy for assimilation (Chen and Zhang (2006)), for the DNAPL have already reached the bottom of the center domain at the sixth step $(t=120 \mathrm{~min})$.

In order to assess the uncertainty of the estimated parameters, the temporal evolutions of the ensemble spread are shown in Fig. 6b. At the end of the assimilation, the ES becomes close to the RMSE, demonstrating that the ensemble variance provides a relatively realistic measure of the uncertainty associated with using the ensemble mean field to represent the reference field. To further quantify the spatial distribution of the uncertainty, slices of the ensemble standard deviation of the $\log k$ field are shown in Fig. 7. It can be noted that the uncertainty is relatively low in the bottom zone (Fig. 7) where the DNAPL accumulated (Fig. 5e). Goodness of the estimation depends on the amount of information given by the observations. There is a large increment of the DNAPL saturation in the bottom zone (Fig. 5). Thus, the observation around is worthier for the estimation and therefore a lower ensemble standard deviation.

Regarding the comparison between the direct and coupled hydrogeophysical inversion result, the direction inversion loses detail information about the fine architecture of the DNAPL plume and lead to overestimation of the DNAPL contaminated area (Fig. 5a and b). However, coupled hydrogeophysical inversion can produce an accurate estimation by directly assimilating the apparent resistivity measurements (Fig. 5i-k). In order to make a quantitative comparison, the $R M S E_{S}(t=80$ and $120 \mathrm{~min}$ ) of direct and coupled hydrogeophysical inversion is depicted in Fig. 8. It shows the $S_{N}$ distribution is reconstructed much better by the $Y$ distribution estimated through the coupled hydrogeophysical inversion $(0.055$ versus 0.097 at $t=120 \mathrm{~min}$ ). Fig. 9 shows scatterplots of true versus estimated values for initial field, coupled hydrogeophysical inversion and direct inversion, for $\log k$ and $S_{N}$, respectively. It can be noted that there is a significant scattering around the 45-degree line for the estimated and reference $S_{N}$ pairs of the direct inversion (Fig. 9e and h). The scatterplots also demonstrate the overestimation of the DNAPL contaminated area by direct inversion, where many ensembles are higher than the 45degree line (Fig. 9e and h). By contrast, the $S_{N}$ values estimated by the coupled inversion match the reference fairly well (Fig. 9d and g).

There are mainly two reasons for the superiority of the coupled hydrogeophysical inversion. For one thing, the DNAPL source zone architecture is highly sensitive to subsurface heterogeneity. This influence is neglected in direct inversion, while it is considered in coupled hydrogeophysical inversion by jointly estimating the subsurface heterogeneity and DNAPL distribution. For another, raw geophysical data (apparent resistivity) is converted to hydrologic state through the traditional geophysical inversion and Archie equation in the direct inversion. However, in its cruder expression (regularization by isotropic smoothing) it has limited applications to invert time-lapse changes in 
$\log k$

Direct

inversion
Reference

distribution

(c)
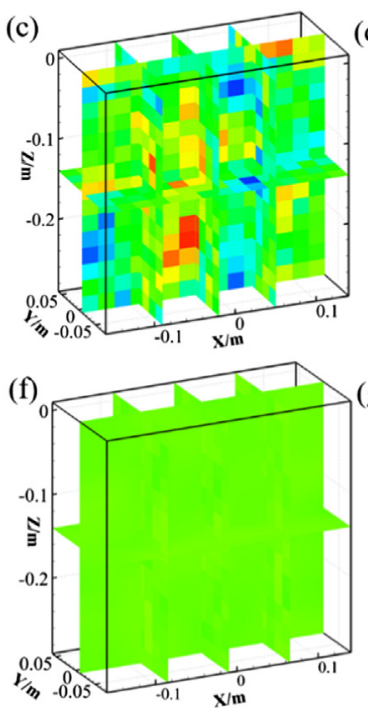

Initial distribution

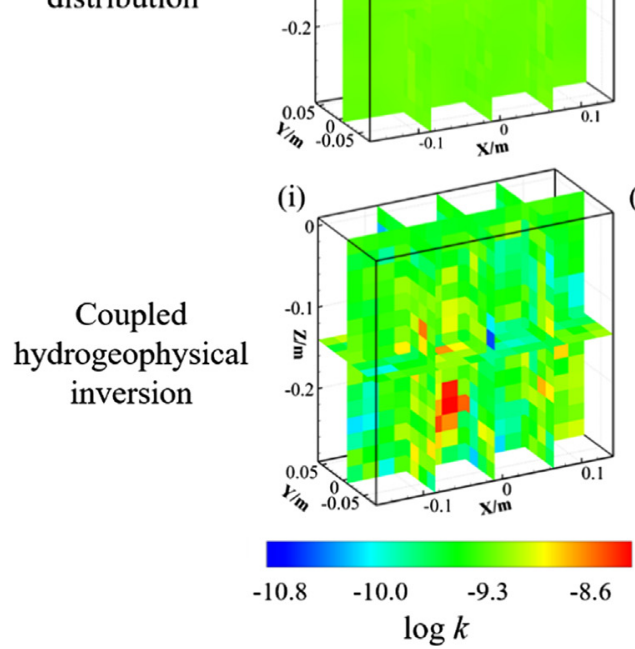

$S_{N}(t=80 \mathrm{~min})$

(a)

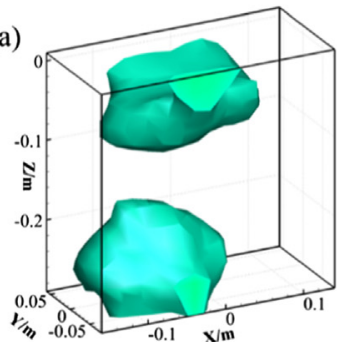

(d)

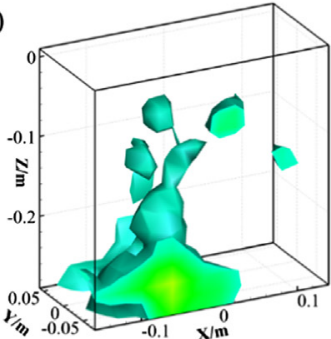

(e)
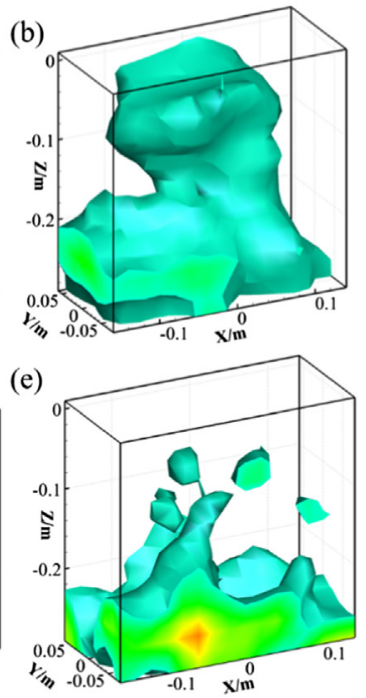
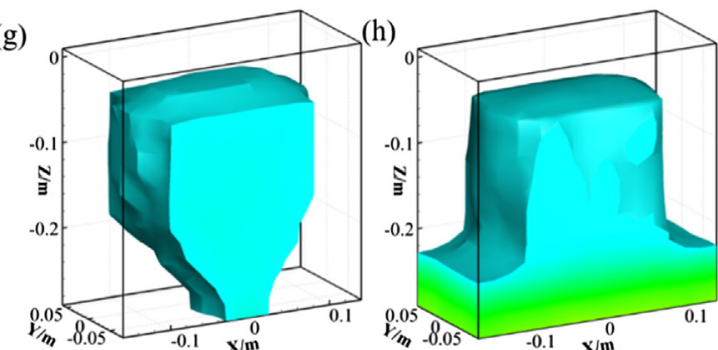

(j)
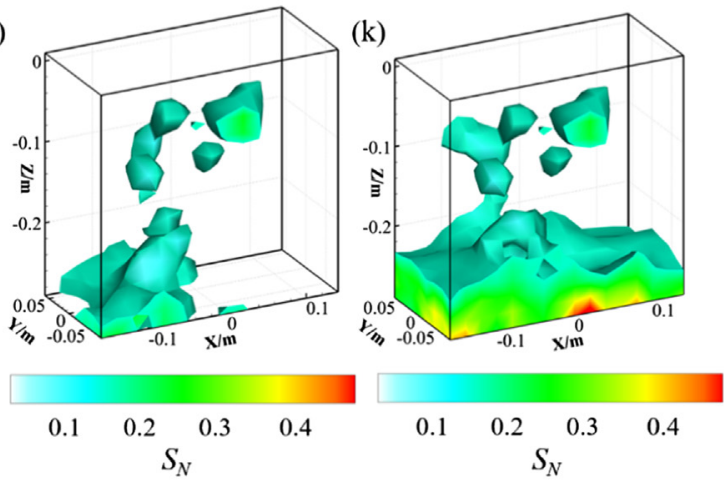

Fig. 5. Direct inversion result, reference distribution, ensemble mean of the initial realizations and coupled hydrogeophysical inversion result after assimilation for $\log k\left(\log _{10}\right.$-permeability) and corresponded DNAPL saturation, respectively, for the synthetic case. A threshold value of $S_{N}=0.15$ is applied for figures for visualization purpose.

(a)

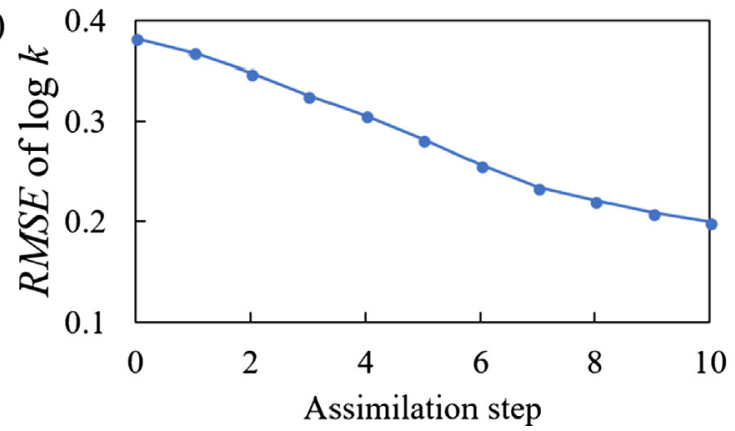

(b) 0.4

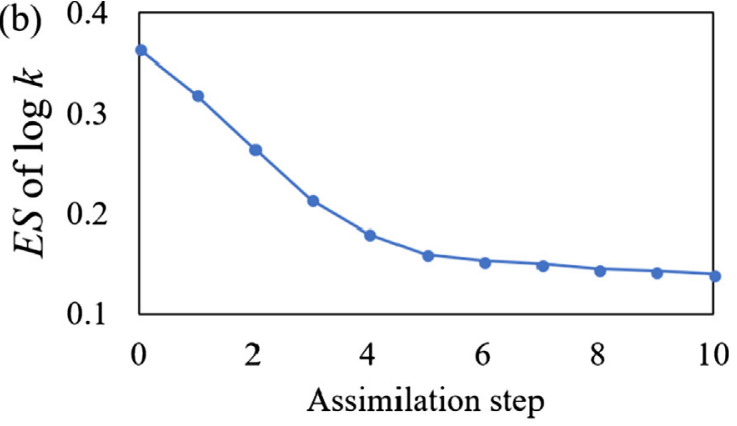

Fig. 6. Evolutions of RMSE (root mean square error) between estimated and reference field (a), and $E S$ (ensemble spread) (b) for $\log _{k}\left(\log _{10}\right.$-permeability), for the synthetic case. 


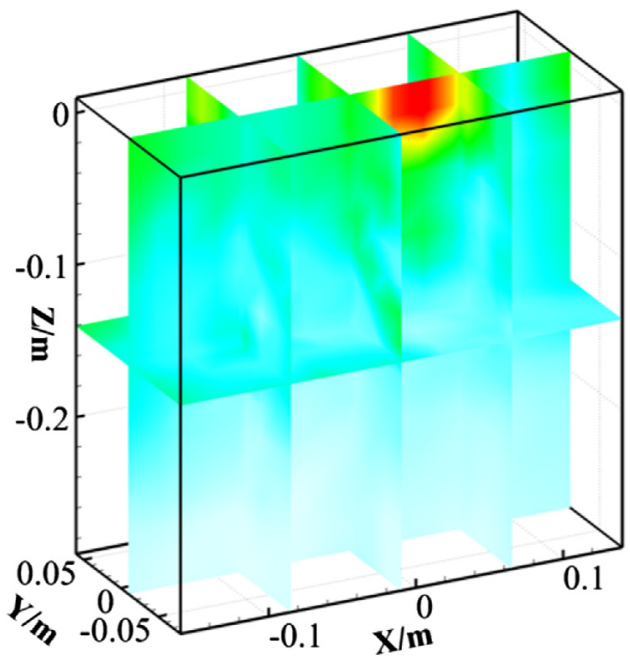

0.42

0.34

0.26

0.18

$\mathbf{0 . 1 0}$

$\mathbf{0 . 0 2}$

Fig. 7. Slices of the ensemble standard deviation of the $\log k$ field at the end of the assimilation for the synthetic case.

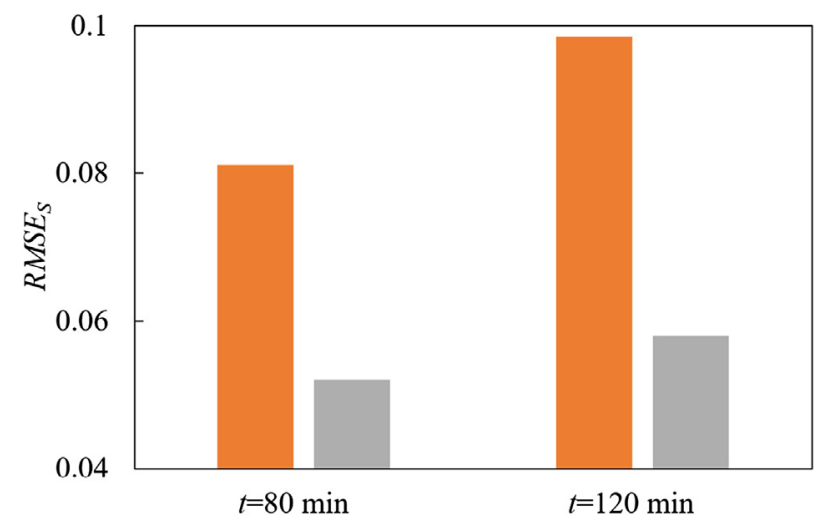

Direct inversion $\square$ Coupled Hydrogeophysical inversion

Fig. 8. The $R M S E_{S}$ (root mean square error of the $S_{N}$ field at $t=80$ and $120 \mathrm{~min}$ ) of direct and coupled hydrogeophysical inversion between estimated and real $S_{N}$ field for the laboratory sandbox experiment.

DNAPL saturations because the smoothing is not realistic in producing physically meaningful resistivity distributions. The coupled hydrogeophysical inversion, which is able to directly translate raw geophysical data into hydrologic state and therefore avoid the artifacts and over-smoothing caused by smoothness constrain and regularization approach (Binley et al., 2015), can produce a more accurate estimation.

The synthetic case demonstrates both the direct and coupled hydrogeophysical inversion can roughly characterize the DNAPL morphology. However, the direct inversion might lose detail information about the fine architecture of the DNAPL plume and overestimate of the contaminated area. On the other hand, the coupled inversion could reproduce a more accurate estimation of the DNAPL source zone architecture, because raw geophysical data is directly converted into hydrologic properties in the coupled inversion, which avoid the oversmoothing and aircrafts caused by smoothness constrain.

\section{Laboratory sandbox experiment}

To evaluate the efficiency of the framework, the proposed data assimilation is applied below to a laboratory sandbox experiment.

\subsection{Direct difference inversion}

With the background and subsequent resistivity obtained from geophysical inversion, the distribution of DNAPL saturation (Fig. 10) is mapped through Eq. (3). In order to distinguish DNAPL plumes from background media, threshold values $\left(S_{N}=0.01\right.$ for Fig. 10a-d and $S_{N}=0.1$ for Fig. 10e-h, determined by trial and error) are applied to the tomography. To illustrate the real-time monitoring responses from the sandbox experimental measurements, eight time-steps were chosen: $t_{1}=100 \mathrm{~min}, t_{2}=200 \mathrm{~min}, t_{3}=300 \mathrm{~min}, t_{4}=400 \mathrm{~min}, t_{5}=800 \mathrm{~min}$, $t_{6}=1200 \mathrm{~min}, t_{7}=2000 \mathrm{~min}$ (the injection is finished) and $t_{8}=7000 \mathrm{~min}$.

Fig. 10 demonstrates that time-lapse ERT data and direct difference inversion method can roughly locate the position of the plumes and depict the temporal evolutions of its general shape. Fig. 10a indicates that DNAPL plumes bypass the first low-permeability layer and accumulate on the second layer at $t_{1}=100 \mathrm{~min}$. From $t_{2}=200 \mathrm{~min}$ to $t_{4}=400 \mathrm{~min}$, DNAPL plumes gradually infiltrate through high-permeability materials (coarse sand) at the second layer and migrate to the third layer (Fig. 10b-d). To depict the major DNAPL plume, a larger threshold $\left(S_{N}=0.1\right)$ is applied to Fig. 10e-h. From $t_{5}=800 \mathrm{~min}$ (Fig. 10e) to $t_{7}=2000 \mathrm{~min}$ (Fig. 10g), DNAPL accumulates on the third layer by degree. At the last time step $t_{8}=7000 \mathrm{~min}$ (Fig. 10h), the image shows no significant difference with $t_{7}=2000 \mathrm{~min}$, which indicates the redistribution of DNAPL is not obvious after the injection is finished at $t_{7}=2000 \mathrm{~min}$.

In order to quantitatively verify the efficiency of ERT and direct inversion, the full-field DNAPL volumes is estimated by Eq. (4). Fig. 11 shows the estimated DNAPL volumes plotted against the true injected volumes. The result demonstrates that the estimated volumes roughly fit the actual volumes line, which validates the feasibility of ERT and direct inversion method. It can be observed that the estimated volumes are very close to the reference at early stage $(V=0-200 \mathrm{ml})$. And an overestimation is noted at middle stage $(V=300-400 \mathrm{ml})$, which is probably caused by the overestimated DNAPL contaminated area. At later stage $(V=800-1000 \mathrm{ml})$, DNAPL volumes are underestimated, probably due to the over-smoothing in geophysical inversion.

Although the direct inversion can roughly characterize the DNAPL morphology, it might lose detail information about the DNAPL plumes. In addition, the estimated DNAPL contaminated area is more extensive than expected, for a part of DNAPL plumes spreads into the low-permeability layer in Fig. 10. There are mainly three reasons responsible for this. First, in cross-borehole ERT survey, the measurement sensitivity will be high close to the boreholes and will be low mid-way between the boreholes. In this work, the limited spatial resolution may lead to the failure of characterizing the fine architecture of the DNAPL. It suggests that survey design optimization is needed to improve the spatial resolution of ERT measurement (Loke et al., 2014). Second, the traditional geophysical inversion of this study is based on smoothness constrain and regularization approach which have been widely used to address problems of ill-posedness and non-uniqueness (Binley et al., 2015). This approach often leads to smoothed image of resistivity. Therefore, it may not work well when sharp contrasts in resistivity exist (de Groot-Hedlin and Constable, 2004). To reduce over-smoothing, Karaoulis et al. (2014) proposes transforming the space and time constraints to be active, meaning that the regularization parameters are distributed rather than being uniform for the entire model. Therefore, the prior information can be incorporated into the inversion scheme in a natural way. Third, ERT data errors and geophysical forward model errors have significant impact on geoelectrical inversion (Binley, 2015). Biased noise level may result in either under-fitting (fail to fully extract the valuable data) or over-fitting (develop the incorrect subsurface geoelectrical structure) in the inversion. Hence, it is important to properly assess the error levels and consider such error levels in the inversion. For instance, Tso et al. (2017) recommends collecting reciprocal data to quantify the data error, although special care should be taken to avoid electrode charge-up effects. In this work, we assumed the noise level (measurement error) is 3\% in general (calculated from the three duplicate background surveys). Maybe it leads to slight under- 


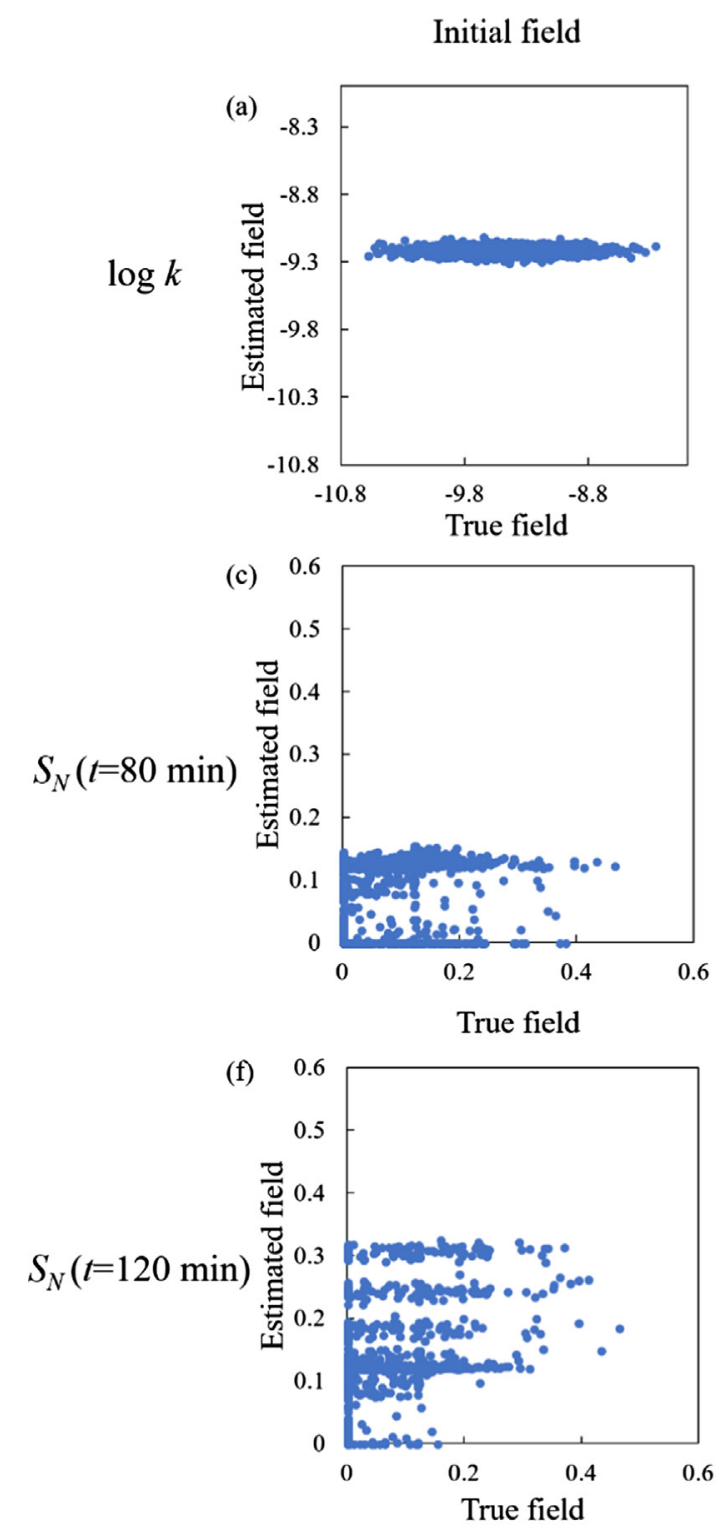

Coupled hydrogeophysical inversion

Direct inversion
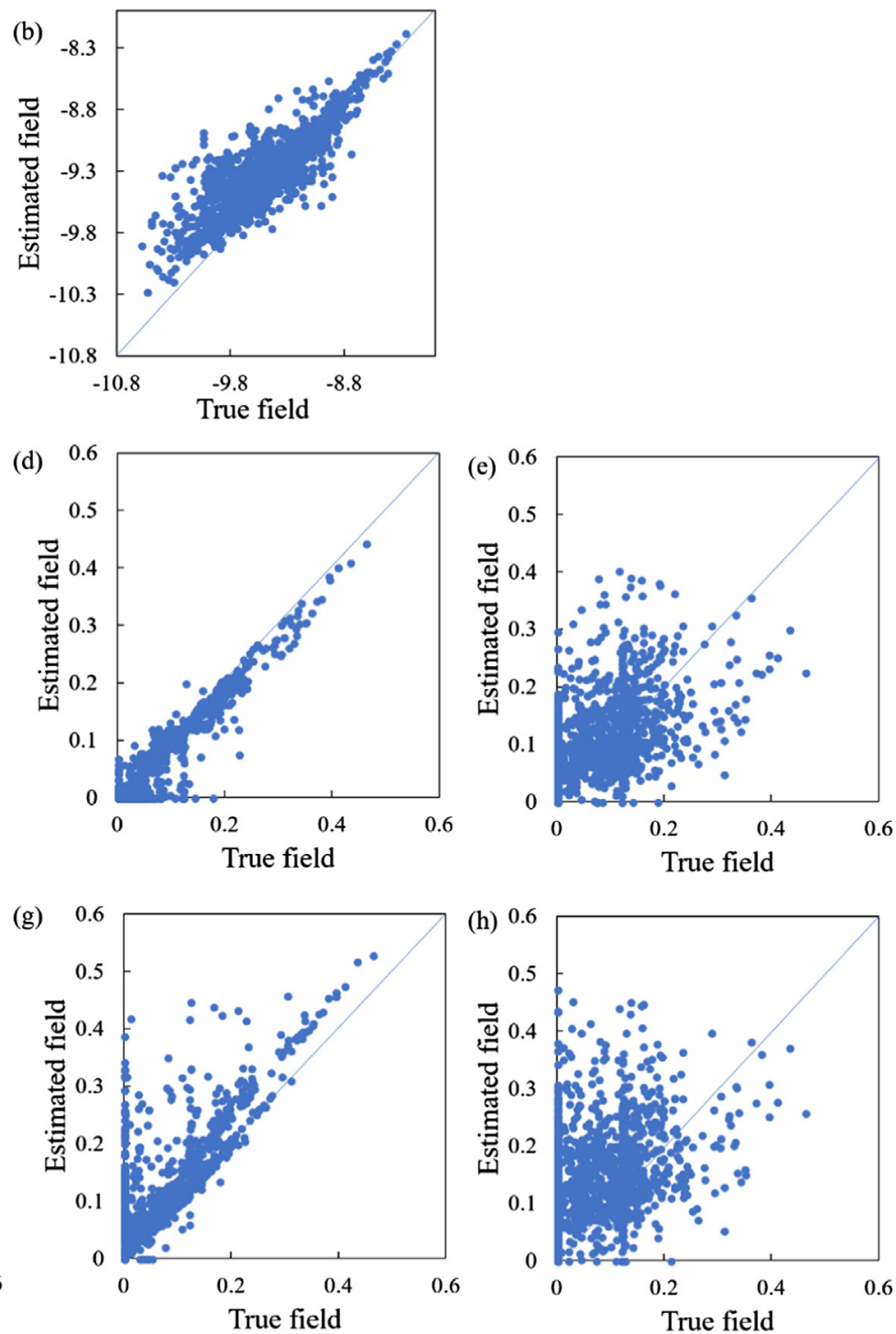

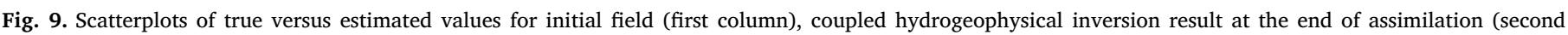

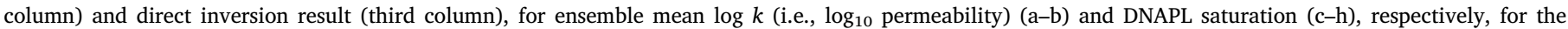
synthetic case.

fitting, and therefore, overestimation of the DNAPL plumes.

\subsection{Coupled hydrogeophysical inversion}

Based on the coupled hydrogeophysical inversion, model parameters and the DNAPL distribution are jointly inversed through assimilating time-lapse ERT data from the laboratory sandbox experiment. First, we analyze the sensitivity of ten parameters: permeability $(k)$, porosity $(\phi)$, parameters in relative permeability function (water residual saturation $S_{w r}$, NAPL residual saturation $S_{n r}$, gas residual saturation $S_{g r}$, fitting coefficients $n^{\prime}$ ) and capillary pressure function (residual liquid saturation $S_{l r}$, van Genuchten $n^{\prime \prime}$, van Genuchten $\alpha_{g n}$, van Genuchten $\alpha_{n w}$ ). The results show that five of them are highly sensitive to the DNAPL migration, including $k, \phi, S_{n r}, n^{\prime}$ and $\alpha_{n w}$. Therefore, these parameters will be estimated in the coupled inversion.

To help constrain the coupled inversion, we use the heterogeneous structure (the spatial distribution of the coarse and fine sand) estimated from the background resistivity image as the known prior information. Fig. 12a shows the background resistivity distribution from direct inversion, the low resistive anomalies at the top is caused by high water content near surface. Note that the background image efficiently explores the lithological structure (the red dotted line in Fig. 12a). Through previous column experiments, we find the bulk resistivity of the fine sand is approximately $13-18 \Omega \mathrm{m}$. Therefore, we assume the zone whose resistivity is lower than $18 \Omega \mathrm{m}$ as fine sand. Then, the prior heterogeneous structure (Fig. 12b) is derived from the background image (Fig. 12a). This heterogeneity structure can roughly reflect the reference lithological structure, but it loses some detail information and it is slightly different from the reference (Fig. 12b and c). With the help of the prior heterogeneity structure, the dimension of the unknown estimated set of parameters drops down to ten (five parameters for coarse and fine sand).

For this laboratory sandbox experiment, the grid discretization, boundary conditions and other parameters (such as cementation exponent and residual liquid saturation), are kept the same as the synthetic case (Table 4). Here, we focus on characterizing the DNAPL source zone architecture and therefore, assume that the location of the contamination source (Fig. 2) is known. After the laboratory 
(a)
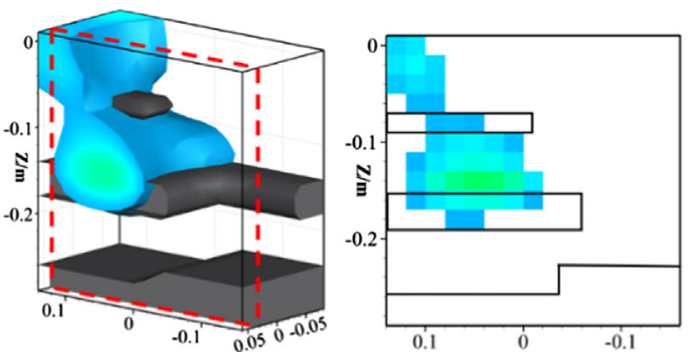

(b)
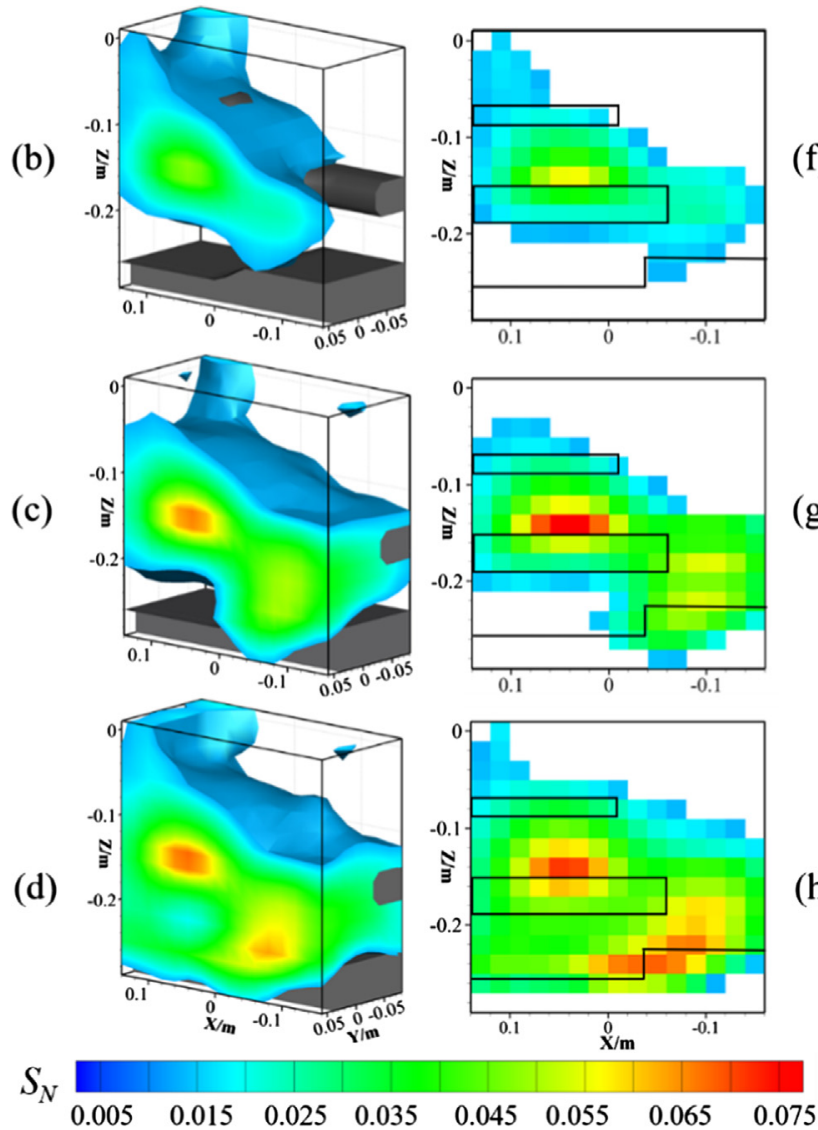

(e)
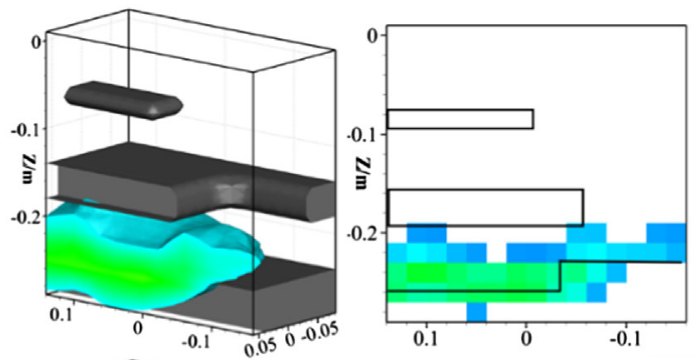

(f)
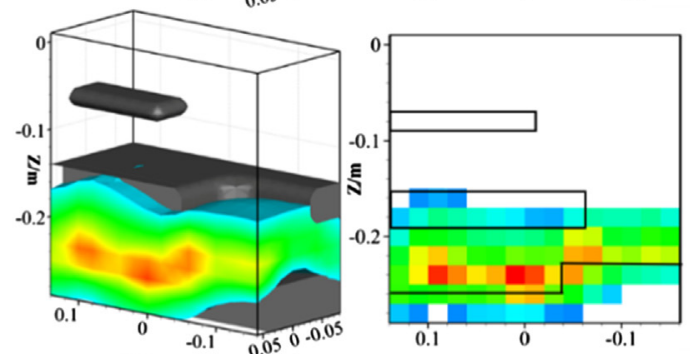

(g)
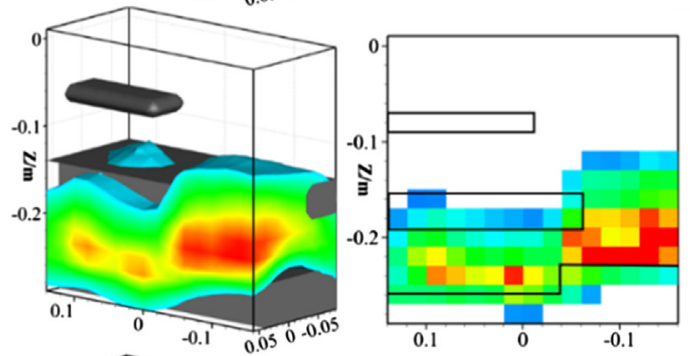

(h)

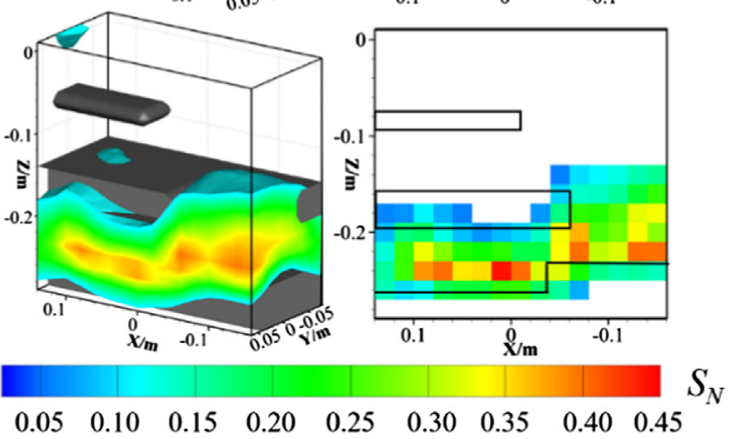

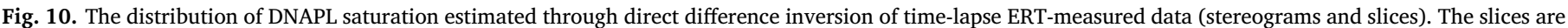

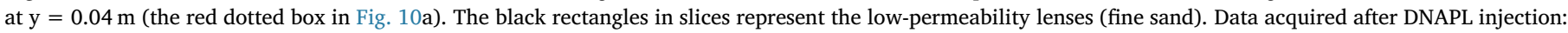

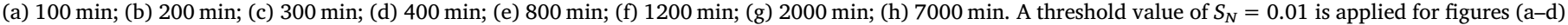

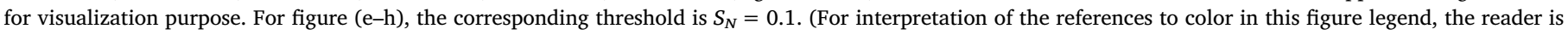
referred to the web version of this article.)

experiment, the absolute permeability and porosity of coarse and fine sand are measured, which are considered as reference parameters in the inversion. In order to generate the initial parameters ensembles, an artificial Gaussian noise is added to the biased parameters mean value with a certain standard deviation (Table 5). The ensemble size is taken as 500 . The total simulation time is kept the same as the sandbox experiment (2000 $\mathrm{min})$, which is equally divided into ten assimilationsteps. Hence, there are a total of ten ERT measurement vectors (each vector includes 1894 apparent resistivity data) available in the inversion. The error of resistivity measurement is assumed as $3 \%$, which is calculated from the three duplicate background surveys.

Fig. 13 shows the temporal evolutions of the estimated parameters in the laboratory sandbox experiment. As can be seen, the estimated parameters gradually converge to the reference. As assimilation goes on, the agreement between the estimated $Y(\log k)$ of coarse sand and the reference improves greatly. At the end of the assimilation, it becomes very close to the reference (Fig. 13a). Nevertheless, the estimated $Y$ of fine sand is unsatisfactory (Fig. 13a). Because DNAPL can hardly infiltrate into the fine sand, the distribution of the DNAPL saturation and the corresponding ERT data can't reflect the permeability of the fine sand. Fig. 12b shows the estimated porosity of coarse and fine sand approximately converges to the reference. The estimated parameters of the relative permeability and capillary pressure function $\left(S_{n r}, n^{\prime}, \alpha_{n w}\right)$ is in agreement with other researches about multiphase fluids simulation and experiment (Mercer and Cohen, 1990; Wilkins et al., 1995; Erning et al., 2012; Al-Raoush, 2014; Robert et al., 2017).

In order to assess the uncertainty of the estimated results, evolutions of the ensemble spread are shown in Fig. 14. If the uncertainty is estimated properly, the ES should be close to the deviation between the measured and the estimated values. As can be seen in Fig. 14a and b, at the end of the assimilation, the ensemble spread roughly matches the deviation line, although it slightly overestimates the uncertainty of the fine sand. Noted that, for all these parameters, the ensemble spread of the coarse sand is lower than the fine sand, which means the estimated parameters for coarse sand is more credible.

Fig. 15 exhibits the reference field, ensemble mean of the initial 


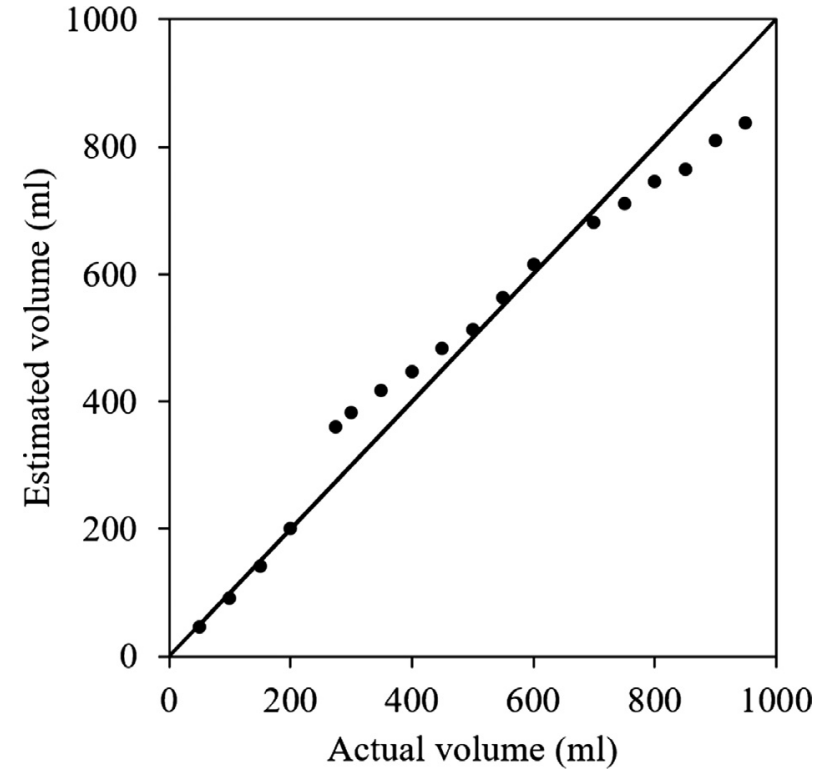

Fig. 11. Comparison of total DNAPL volumes calculated by ERT monitoring versus the actual injected volumes. The solid line represents the 1:1 perfect fit for reference purpose.

realizations and estimated field at the end of the assimilation for $\log k$ and corresponded DNAPL saturation distribution, respectively. In order to distinguish the DNAPL saturation distribution at different stage ( $t=400 \mathrm{~min}$ and $t=1200 \mathrm{~min}$ ), different color scale and threshold values $\left(S_{N}=0.01\right.$ for Fig. $15 \mathrm{~d}-\mathrm{g}$ and $S_{N}=0.1$ for Fig. $\left.15 \mathrm{~h}-\mathrm{k}\right)$ are applied to the tomography. Noted that it is quite difficult to acquire a real DNAPL distribution in such 3D sandbox experiment. Therefore, in this work, based on the measured parameters values (permeability and porosity), the estimated parameters values $\left(S_{n r}, n^{\prime}, \alpha_{n w}\right)$ from coupled inversion, the actual lithological structure and boundary condition, we developed a T2VOC model to simulate the actual DNAPL migration and distribution. Although the simulation results (Fig. $15 \mathrm{~d}$ and h) may slightly deviate from the true field, it can represent the "true" (reference) DNAPL distribution to a certain extent. Fig. 15a and b shows that there is a significant mismatch between the reference and initial $Y$ $(\log k)$ values. However, the $Y$ values estimated by the coupled inversion become closer to the reference (Fig. 15c). With the retrieved parameters, the DNAPL distribution can be better delineated (Fig. $15 \mathrm{f}$ and $\mathrm{j}$ ). In contrast, with the initial parameters, the DNAPL migrates more slowly, due to the biased permeability value (Fig. 15e and i).

To quantitatively analyze the performance of the coupled hydrogeophysical inversion, temporal evolutions of RMSE between the
Table 5

Numerical model parameters for the real-world sandbox case.

\begin{tabular}{lllllll}
\hline \multirow{2}{*}{ Measured } & & $\log k\left(\mathrm{~m}^{2}\right)$ & Porosity & $S_{n r}$ & $n^{\prime}$ & $\alpha_{n w}\left(\mathrm{~m}^{-1}\right)$ \\
& Coarse sand & -9.52 & 0.35 & & & \\
& Fine sand & -10.56 & 0.37 & & & \\
\multirow{5}{*}{ Initial } & Coarse sand (mean) & -10.17 & 0.25 & 0.08 & 3.5 & 20 \\
& $\sigma$ & 0.24 & 0.2 & 0.05 & 0.5 & 2 \\
& Fine sand (mean) & -10.78 & 0.35 & 0.15 & 2.5 & 5 \\
& $\sigma$ & 0.24 & 0.2 & 0.05 & 0.5 & 2 \\
\multirow{5}{*}{ Estimated } & Coarse sand (mean) & -9.54 & 0.33 & 0.06 & 2.85 & 16.4 \\
& Fine sand (mean) & -10.7 & 0.36 & 0.19 & 2.63 & 9.2 \\
\hline
\end{tabular}

Note that $\log k$ represents $\log _{10}$ (permeability); $\sigma$ represents the standard deviation of the parameters realizations.

estimated $S_{N}$ and the reference $S_{N}$ (represented by the T2VOC simulation with the actual parameters, $t=1200 \mathrm{~min}$ ) is depicted in Fig. 16. It shows the estimated parameters can successfully reflect the distribution of DNAPL and the agreement between the reference and estimated $S_{N}$ field is increasing.

Compared with direct difference inversion (Fig. 15g and k), coupled hydrogeophysical inversion provides better recovery of the DNAPL source zone architecture (Fig. $15 \mathrm{f}$ and j). At $t=400$ and $1200 \mathrm{~min}$, the contaminant area estimated by direct inversion is more extensive than expected (Fig. 15g and k). While it is constrained in the high- permeability zone (coarse sand) in the coupled inversion (Fig. 15f and j). However, more information is needed in the coupled inverse problem to reduce its non-uniqueness. For the laboratory sandbox experiment, the lithological structure (the spatial distribution of the coarse and fine sand), the petrophysical relationship parameters (e.g., the cementation exponent) and the location of the DNAPL leakage source are assumed as the known prior information for the coupled inversion. Researches demonstrate that with biased prior information of the parameter field and inaccurate petrophysical relationship, the coupled inversion might result in filter inbreeding and convergence on the wrong solution (Camporese et al. 2015; Brunetti and Linde (2018)). Therefore, to help constrain the coupled inversion, multiple types of data (e.g., induced polarization data and well-logged data) should be incorporated in the future.

Although the laboratory sandbox experiment is a simple inversion problem in which only ten parameters are estimated, this framework can be easily applied to realistic scenarios where the subsurface heterogeneity and DNAPL source zone architecture are more complicated.

\section{Conclusions}

We have performed synthetic and laboratory sandbox experiments to model the infiltration of DNAPLs in a heterogeneous porous material
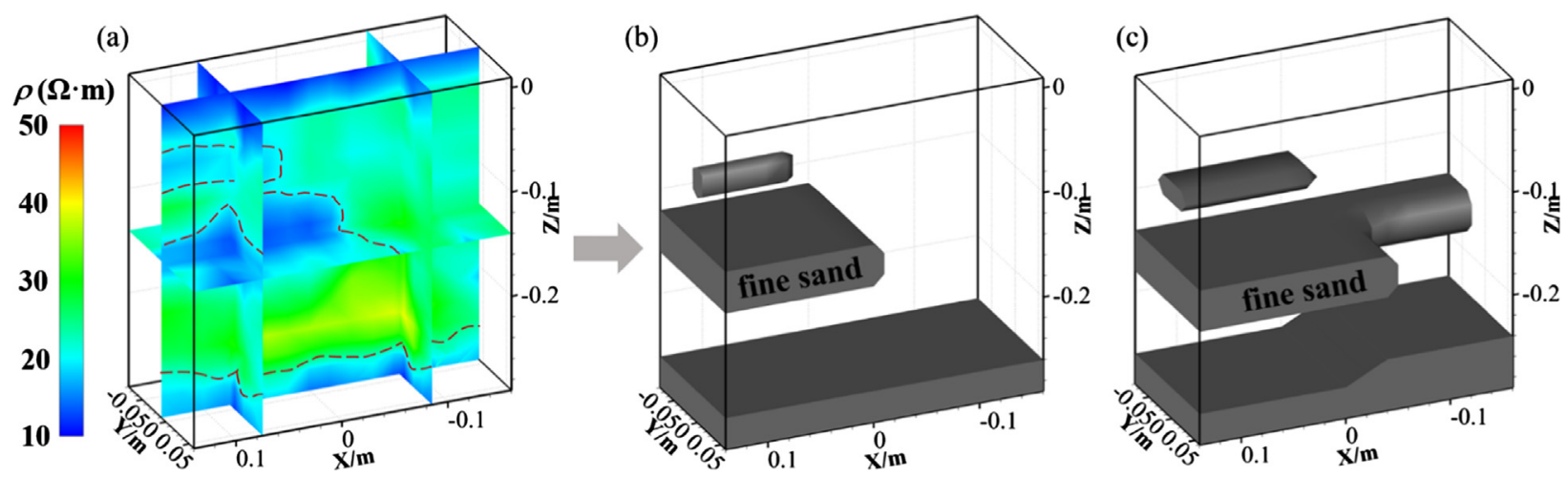

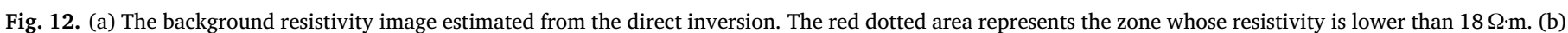

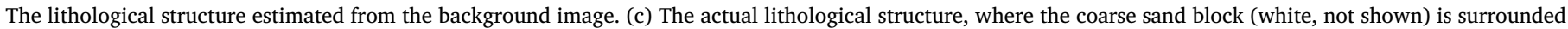
by the fine sand (dark gray). (For interpretation of the references to color in this figure legend, the reader is referred to the web version of this article.) 
(a)

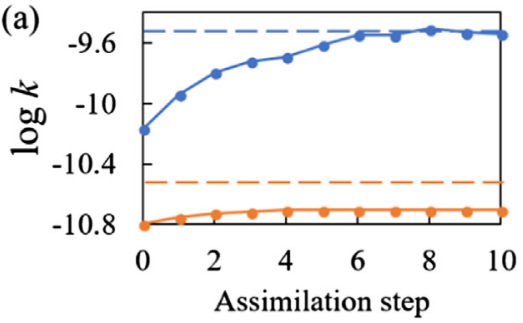

$\rightarrow-$ estimated value (coarse sand) $\rightarrow-$ estimated value (fine sand)

-- measured value (coarse sand) $\quad---$ measured value (fine sand) (b) 0.4

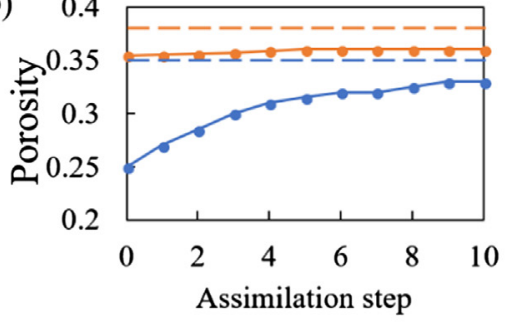

(c)

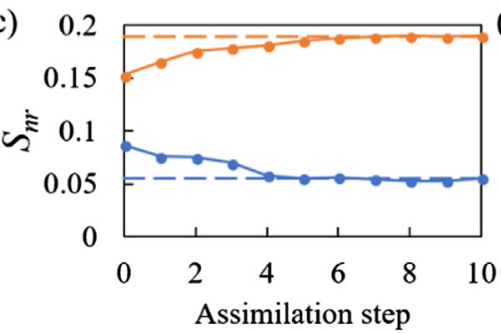

$\rightarrow$ estimated value (coarse sand)

- - reference value used in T2VOC (coarse sand) (d)

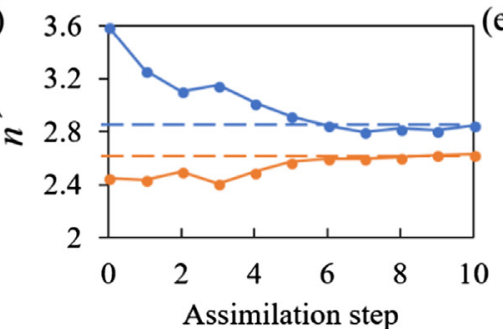

(e)

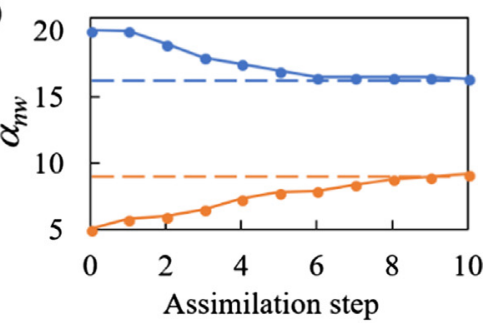

$\rightarrow$ estimated value (fine sand)

- - - reference value used in T2VOC (fine sand)

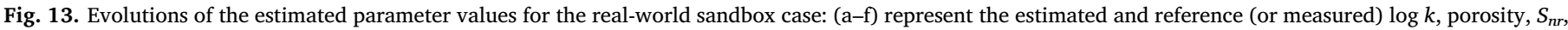

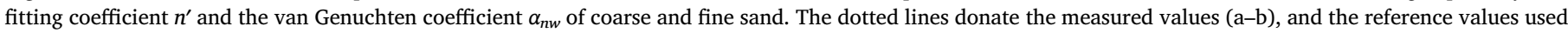
in T2VOC simulation (c-e), respectively.

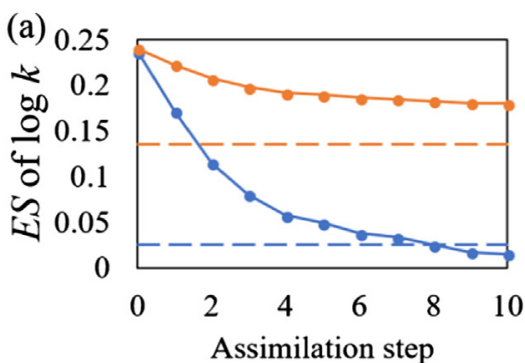

(d)

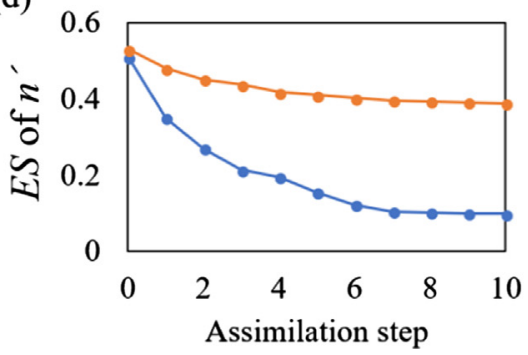

(b)

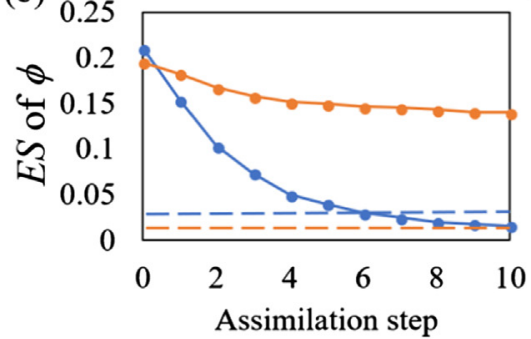

(e)

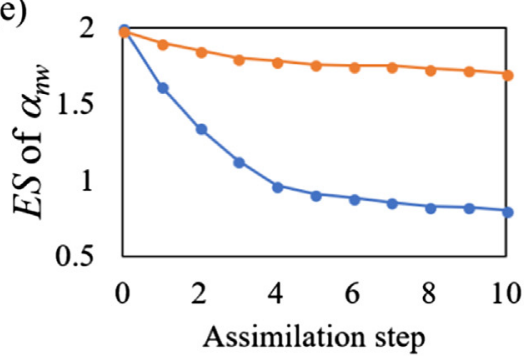

(c)

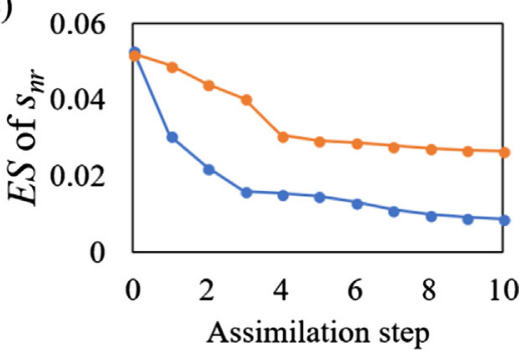

Legend

$\rightarrow$-coarse sand $\rightarrow$-fine sand

- - deviation for fine sand

-- deviation for coarse sand

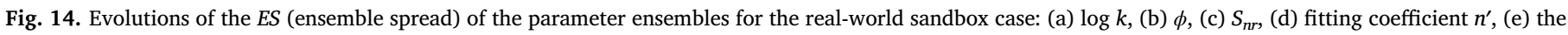

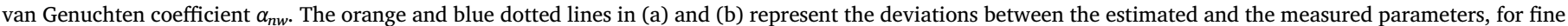
sand and coarse sand, respectively. (For interpretation of the references to color in this figure legend, the reader is referred to the web version of this article.)

characterized different grain sizes. These infiltrations were monitored by time-lapse cross-borehole ERT measurements. We proposed a coupled hydrogeophysical inversion scheme to jointly estimate the DNAPL source zone architecture and heterogeneous permeability field by assimilating time-lapse cross-borehole ERT data using the ensemble Kalman filter (EnKF) approach. To demonstrate the performance of the coupled inversion with respect to the classical deterministic ERT inversion approach, we apply these two techniques to the synthetic and laboratory experiments with DNAPL infiltrating of 3D sandbox. The results show that time-lapse ERT and the classical time-lapse inversion can locate the morphology of the DNAPL plume with some uncertainty. That said, the classical ERT inversion approach misses detailed information about the discontinuous ganglia of the DNAPL plume and lead to an overestimation of the contaminated area. The coupled inversion is able to accurately reproduce both the DNAPL source zone architecture and the heterogeneous permeability field. This improvement occurs because the coupled inversion directly converts raw geophysical data into hydrologic properties, therefore, alleviating oversmoothing caused by the traditional geophysical inversion.

The synthetic and laboratory experiments demonstrate the ability of 


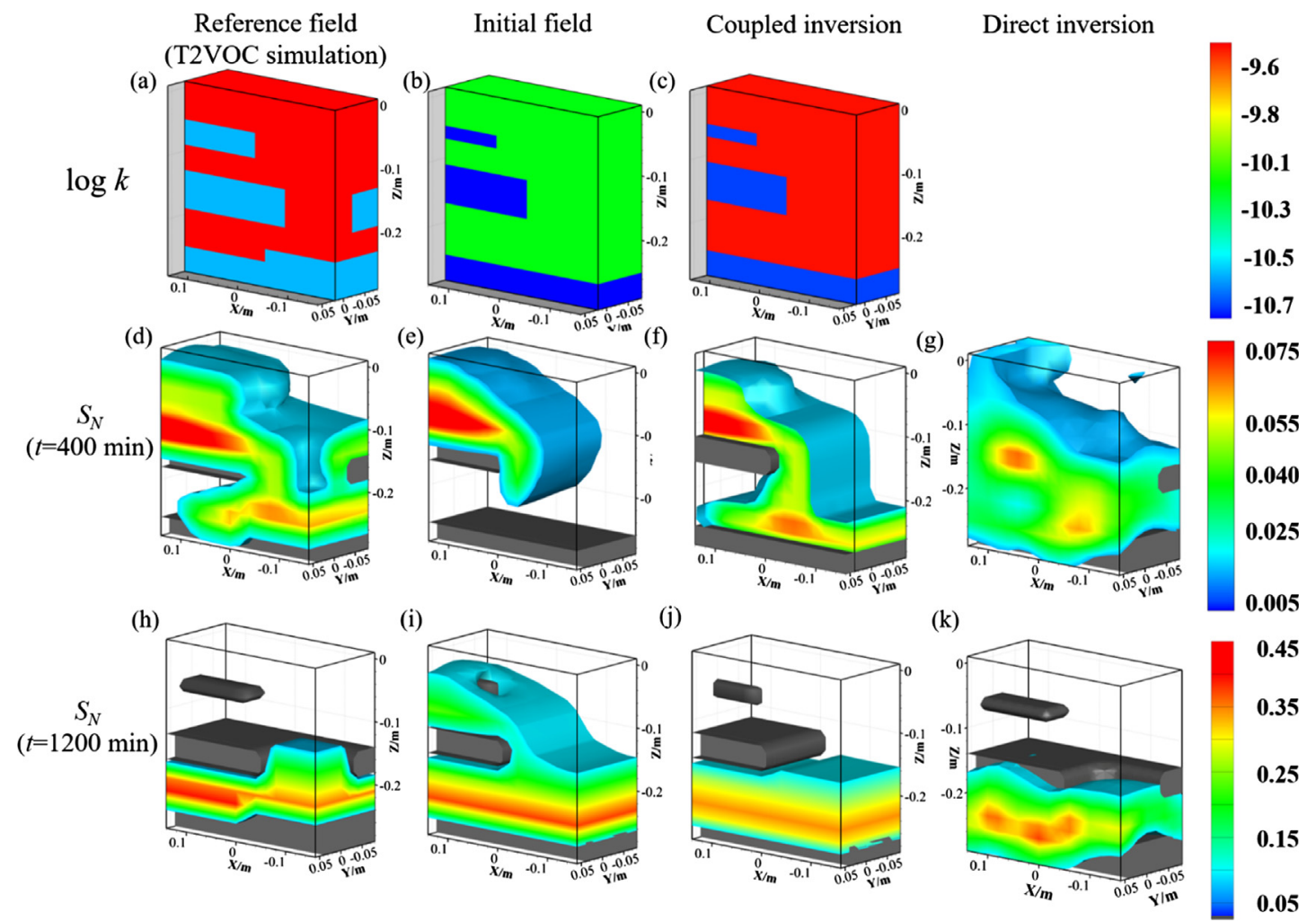

Fig. 15. Reference field, ensemble mean of the initial realizations and estimated field at the end of the assimilation for log $k$ (a-c) and corresponding DNAPL saturation distribution (d-k), respectively, for the laboratory sandbox experiment. A threshold value of $S_{N}=0.01$ is applied for figures (d-g) for visualization purpose. For figure (h-k), the corresponding threshold is $S_{N}=0.1$.

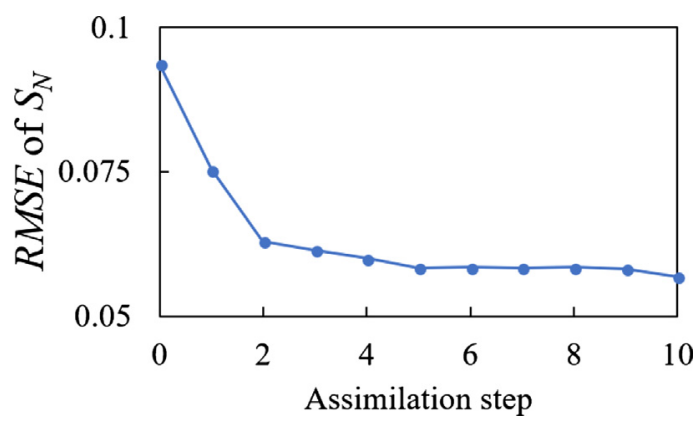

Fig. 16. Evolutions of RMSE (root mean square error) between estimated and reference $S_{N}$ field at $t=1200 \mathrm{~min}$ for the laboratory sandbox experiment.

time-lapse electrical resistivity data and the coupled hydrogeophysical inversion to accurately characterize the subsurface heterogeneity and DNAPL distribution over time. However, there are still situations where the coupled inversion should be taken into account (i.e., the background ERT data and boreholes might not be available) and further studies in this field are necessary (i.e., the petrophysics influenced by the NAPL configuration and biodegradation). In the future, a combination of various types of geophysical data (including induced polarization data and ground penetrating radar) together with hydrogeochemical data (i.e., downgradient aqueous-phase concentration) will be considered to help better constrain this type of problem.

\section{Acknowledgements}

This work was financially supported by the National Nature Science Foundation of China grants (No. 41672229 and U1503282). We are grateful to the Associate Editor, Dr. Majken Looms Zibar and three anonymous reviewers for their insightful comments and suggestions, which significantly improve the quality of this work.

\section{References}

AGI. 2010. EarthImager ${ }^{\mathrm{TM}}$ 2D and 3D, Resistivity and IP Inversion Software. Advanced Geosciences Incorporated. http://www.agiusa.com.

Al-Raoush, R.I., 2014. Experimental investigation of the influence of grain geometry on residual NAPL using synchrotron microtomography. J. Contam. Hydrol. 159, 1-10. https://doi.org/10.1016/j.jconhyd.2014.01.008.

Archie, G.E., 1942. The electrical resistivity log as an aid in determining some reservoir characteristics. Trans. Am. Ind. Min. Metall. Pet. Eng. 146 (01), 54-62. https://doi. org/10.2118/942054-g.

Atekwana, E.A., Abdel Aal, G.Z., 2015. Iron biomineralization controls on geophysical signatures of hydrocarbon contaminated sediments. J. Earth Sci. 26 (6), 835-843. https://doi.org/10.1007/s12583-015-0611-2.

Atekwana, E.A., Atekwana, E.A., 2010. Geophysical signatures of microbial activity at hydrocarbon contaminated sites: a review. Surv. Geophys. 31 (2), 247-283. https:// doi.org/10.1007/s10712-009-9089-8.

Berg, C., 2007. An effective medium algorithm for calculating water saturation at any frequency. Geophysics 72 (2), E59-E67.

A. Binley A. Kemna 2005129156 10.1007/1-4020-3102-5_5.

Binley, A., 2015. 11.08-Tools and techniques: electrical methods. In: Treatise on Geophysics, second ed. Elsevier, Oxford, pp. 233-259. https://doi.org/10.1016/ B978-0-444-53802-4.00192-5.

Binley, A., et al., 2015. The emergence of hydrogeophysics for improved understanding of subsurface processes over multiple scales. Water Resour. Res. 51 (6), 3837-3866. https://doi.org/10.1002/2015WR017016.

Brunetti, C., Linde, N., 2018. Impact of petrophysical uncertainty on Bayesian hydrogeophysical inversion and model selection. Adv. Water Resour. 111, 346-359. https://doi.org/10.1016/j.advwatres.2017.11.028.

Camporese, M., Cassiani, G., Deiana, R., Salandin, P., Binley, A., 2015. Coupled and uncoupled hydrogeophysical inversions using ensemble Kalman filter assimilation of ERT-monitored tracer test data. Water Resour. Res. 51, 3277-3291. https://doi.org/ 10.1002/2014WR016017.

Chambers, J.E., Loke, M.H., Ogilvy, R.D., Meldrum, P.I., 2004. Noninvasive monitoring of DNAPL migration through a saturated porous medium using electrical impedance tomography. J. Contam. Hydrol. 68, 1. https://doi.org/10.1016/S0169-7722(03) 00142-6.

Chambers, J.E., Wilkinson, P.B., Wealthall, G.P., Loke, M.H., Dearden, R., Wilson, R., Allen, D., Ogilvy, R.D., 2010. Hydrogeophysical imaging of deposit heterogeneity and groundwater chemistry changes during DNAPL source zone bioremediation. J. Contam. Hydrol. 118, 43-61. https://doi.org/10.1016/j.jconhyd.2010.07.001. 
Chen, Y., Zhang, D., 2006. Data assimilation for transient flow in geologic formations via ensemble Kalman filter. Adv. Water Resour. 29 (8), 1107-1122. https://doi.org/10. 1016/j.advwatres.2005.09.007.

de Groot-Hedlin, C., Constable, S., 2004. Inversion of magnetotelluric data for 2D structure with sharp resistivity contrasts. Geophysics 69 (1), 78-86. https://doi.org/ $10.1190 / 1.1649377$

Deng, Y., Shi, X., Xu, H., Sun, Y., Wu, J., Revil, A., 2017. Quantitative assessment of electrical resistivity tomography for monitoring DNAPLs migration - comparison with high-resolution light transmission visualization in laboratory sandbox. J. Hydrol. 544, 254-266. https://doi.org/10.1016/j.jhydrol.2016.11.036.

Deutsch, C.V., Journel, A.G., 1998. Geostatistical Software Library and User's Guide, second ed. Oxford University Press, New York http://www.scopus.com/inward/record.url?eid = 2-s2.0-0031916947\&partnerID = tZOtx3y1.

Dwarakanath, V., Jackson, R.E., Pope, G.A., 2002. Influence of wettability on the recovery of NAPLs from alluvium. Environ. Sci. Technol. 36, 227-231. https://doi.org/ 10.1021/es011023w.

Erning, K., Grandel, S., Dahmke, A., Schäfer, D., 2012. Simulation of DNAPL infiltration and spreading behaviour in the saturated zone at varying flow velocities and alternating subsurface geometries. Environ. Earth Sci. 65, 1119-1131. https://doi.org/10. 1007/s12665-011-1361-9.

Evensen, G., 2009. The ensemble Kalman filter for combined state and parameter estimation. IEEE Contr. Syst. Mag. 29, 83-104. https://doi.org/10.1109/MCS.2009. 932223.

Falta, R.W., Pruess, K., Finsterle, S., Battistelli, A. 1995. T2VOC User's Guide. Lawrence Berkley Laboratory, Report LBL-36400: 1-155. https://doi.org/10.2172/89501.

Ferrari, A., Jimenez Martinez, J., Borgne, T.L., Méheust, Y., Lunati, I., 2015. Challenges in modeling unstable two-phase flow experiments in porous micromodels. Water Resour. Res. 51, 1381-1400. https://doi.org/10.1002/2014WR016384.

Gelius, L.J., Wang, Z., 2008. Modelling production caused changes in conductivity for a siliciclastic reservoir: a differential effective medium approach. Geophys. Prospect. 56, 677-691. https://doi.org/10.1111/j.1365-2478.2008.00720.x.

Goes, B., Meekes, J., 2004. An effective electrode configuration for the detection of DNAPLs with electrical resistivity tomography. J. Environ. Eng. Geophys. 9, 127-141. https://doi.org/10.4133/JEEG9.3.127.

Hanai, T., 1960. Theory of the dielectric dispersion due to the interfacial polarization and its application to emulsions. Kolloid-Zeitschrift 171, 23-31. https://doi.org/10.1007/ BF01520320.

Hinnell, A.C., Ferré, T.P.A., Vrugt, J.A., Huisman, J.A., Moysey, S., Rings, J., Kowalsky, M.B., 2010. Improved extraction of hydrologic information from geophysical data through coupled hydrogeophysical inversion. Water Resour. Res. 46 (4), 475-478. https://doi:10.1029/2008WR007060.

Hölz, S., Swidinsky, A., Sommer, M., Jegen, M., Bialas, J., 2015. The use of rotational invariants for the interpretation of marine CSEM data with a case study from the North Alex mud volcano, West Nile Delta. Geophys. J. Int. 201, 224-245. https://doi. org/10.1093/gji/ggv015.

Irving, J., Singha, K., 2010. Stochastic inversion of tracer test and electrical geophysical data to estimate hydraulic conductivities. Water Resour. Res. 46 (11), W11514. https://doi:10.1029/2009WR008340.

Jardani, A., Revil, A., Dupont, J.P., 2013. Stochastic joint inversion of hydrogeophysical data for salt tracer test monitoring and hydraulic conductivity imaging. Adv. Water Resour. 52, 62-77. https://doi.org/10.1016/j.advwatres.2012.08.005.

Johansson, S., Fiandaca, G., Dahlin, T., 2015. Influence of non-aqueous phase liquid configuration on induced polarization parameters: Conceptual models applied to a time-domain field case study. J. Appl. Geophys. 123, 295-309. https://doi.org/10. 1016/j.jappgeo.2015.08.010.

Johnson, T.C., Versteeg, R.J., Ward, A., Day-Lewis, F.D., Revil, A., 2010. Improved hydrogeophysical characterization and monitoring through parallel modeling and inversion of time-domain resistivity and induced-polarization data. Geophysics 75 , A27-A41. https://doi.org/10.1190/1.3475513.

Karaoulis, M., Kim, J., Tsourlos, P., 2011a. 4D active time constrained resistivity inversion. J. Appl. Geophys. 73 (1), 25-34. https://doi.org/10.1016/j.jappgeo.2010.11. 002.

Karaoulis, M., Revil, A., Werkema, D.D., Minsley, B.J., Woodruff, W.F., Kemna, A., 2011b. Time-lapse three-dimensional inversion of complex conductivity data using an active time constrained (ATC) approach. Geophys. J. Int. 187, 237-251. https://doi.org/10. 1111/j.1365-246X.2011.05156.x.

Karaoulis, M., Tsourlos, P., Kim, J.H., Revil, A., 2014. 4D time-lapse ERT inversion: introducing combined time and space constraints. Near Surf. Geophys. 12 (1), 25-34. https://doi:10.3997/1873-0604.2013004.

Koch, J., Nowak, W., 2015. Predicting DNAPL mass discharge and contaminated site longevity probabilities: Conceptual model and high-resolution stochastic simulation. Water Resour. Res. 51, 806-831. https://doi.org/10.1002/2014WR015478.

Koch, J., Nowak, W., 2016. Identification of contaminant source architectures-a statistical inversion that emulates multiphase physics in a computationally practicable manner. Water Resour. Res. 52, 1009-1025. https://doi.org/10.1002/2015WR017894.

Kueper, B.H., Stroo, H.F., Vogel, C.M., Ward, C.H., 2014. Chlorinated Solvent Source Zone Remediation. Springer, New York.

LaBrecque, D.J., Yang, X., 2001. Difference inversion of ERT Data: a fast inversion method for 3-D in situ monitoring. J. Environ. Eng. Geophys. 6, 316-321. https://doi.org/10. 4133/JEEG6.2.83

Lenhard, R.J., Parker, J.C., Kaluarachchi, J.J., 1989. A model for hysteretic constitutive relations governing multiphase flow: 3 . Refinements and numerical simulations. Water Resour. Res. 25, 1727-1736. https://doi.org/10.1029/WR023i012p02187.

Liang, L., Abubakar, A., Habashy, T.M., 2016. Reservoir property mapping and monitoring from joint inversion of time-lapse seismic, electromagnetic, and production data. Geophysics 81, D73-D84. https://doi.org/10.1190/geo2015-0620.1.
Loke, M.H. 2001. Tutorial: 2D and 3D electrical imaging surveys. Penang, Malaysia, Universiti Sains Malaysia. Unpublished course notes, http://www. geoelectric. com.

Loke, M.H., Wilkinson, P.B., Uhlemann, S.S., Chambers, J.E., Oxby, L.S., 2014. Computation of optimized arrays for 3-D electrical imaging surveys. Geophys. J. Int. 199 (3), 1751-1764. https://doi:10.1093/gji/ggu357.

Lucius, J.E., Olhoeft, G.R., Hill, P.L., Duke, S.K., 1992. Properties and hazards of 108 selected substances-1992 edition. US Geological Survey Open-File Report 92, 527-554. https://pubs.usgs.gov/of/1989/0491/report.pdf.

Mboh, C.M., Huisman, J.A., Van, G.N., Rings, J., Vereecken, H., 2012. Coupled hydrogeophysical inversion of electrical resistances and inflow measurements for topsoil hydraulic properties under constant head infiltration. Near Surf. Geophys. 10 (5), 413-426. https://doi:10.3997/1873-0604.2012009.

Mercer, J.W., Cohen, R.M., 1990. A review of immiscible fluids in the subsurface: properties, models, characterization and remediation. J. Contam. Hydrol. 6, 107-163. https://doi.org/10.1016/0169-7722(90)90043-G.

Morrissey, F.A., Grismer, M.E., 1999. Kinetics of volatile organic compound sorption/ desorption on clay minerals. J. Contam. Hydrol. 36, 291-312. https://doi.org/10. 1016/S0169-7722(98)00150-8.

National Research Council, 2005. Contaminants in the subsurface: source zone assessment and remediation. In: Washington, D.C. (Ed.), National Research Council.

National Research Council, 2013. Alternatives for managing the nation's complex contaminated groundwater sites. In: Washington, D.C. (Ed.), National Research Council.

Naudet, V., Gourry, J.C., Girard, F., Matthieu, F., Saada, A., 2014. 3D electrical resistivity tomography to locate DNAPL contamination around a housing estate. Near Surf. Geophys. 12, 351-360. https://doi.org/10.3997/1873-0604.2012059.

Newell, C.J., Kueper, B.H., Wilson, J.T., Johnson, P.C., 2014. Natural Attenuation of Chlorinated Solvent Source Zones. Springer, pp. 459-508.

Olhoeft, G.R., 1992. Geophysical Detection of Hydrocarbon and Organic Chemical Contamination. Society of Exploration Geophysicists, pp. 587-595.

Orlando, L., Renzi, B., 2015. Electrical permittivity and resistivity time lapses of multiphase DNAPLs in a lab test. Water Resour. Res. 51, 377-389. https://doi.org/10. 1002/2014WR015291.

Parker, J.C., Lenhard, R.J., 1987. A model for hysteretic constitutive relations governing multiphase flow 1. saturation-pressure relations. Water Resour. Res. 23, 2187-2196. https://doi.org/10.1029/WR023i012p02187.

Patnode, H.W., Wyllie, M.R.J., 1950. The presence of conductive solids in reservoir rocks as a factor in electric log interpretation. J. Pet. Technol. 2, 47-52. https://doi.org/10. 2118/950047-G.

Petri, B.G., Fučík, R., Illangasekare, T.H., Smits, K.M., Christ, J.A., Sakaki, T., Sauck, C.C., 2015. Effect of NAPL source morphology on mass transfer in the vadose zone. Groundwater 53, 685-698. https://doi.org/10.1111/gwat.12284.

Pollock, D., Cirpka, O.A., 2012. Fully coupled hydrogeophysical inversion of a laboratory salt tracer experiment monitored by electrical resistivity tomography. Water Resour. Res. 48 (1), W01505. http://doi:10.1029/2011WR010779.

Power, C., Gerhard, J.I., Karaoulis, M., Tsourlos, P., Giannopoulos, A., 2014. Evaluating four-dimensional time-lapse electrical resistivity tomography for monitoring DNAPL source zone remediation. J. Contam. Hydrol. 162-163, 27-46. https://doi.org/10. 1016/j.jconhyd.2014.04.004.

Power, C., Gerhard, J.I., Tsourlos, P., Giannopoulos, A., 2013. A new coupled model for simulating the mapping of dense nonaqueous phase liquids using electrical resistivity tomography. Geophysics 78, N1-N15. https://doi.org/10.1190/geo2012-0395.1.

Power, C., Gerhard, J.I., Tsourlos, P., Soupios, P., Simyrdanis, K., Karaoulis, M., 2015 Improved time-lapse electrical resistivity tomography monitoring of dense non-aqueous phase liquids with surface-to-horizontal borehole arrays. J. Appl. Geophys. 112 1-13. https://doi.org/10.1016/j.jappgeo.2014.10.022.

Pruess, K. 1983. Development of the General Purpose Simulator MULKOM, Report LBL15500 Lawrence Berkeley National Laboratory http://www.iaea.org/inis/collection/ NCLCollectionStore/Public/16/022/16022252.pdf.

Pruess, K., Battistelli, A. 2002. TMVOC, A Numerical Simulator for Three-Phase NonIsothermal Flows of Multicomponent Hydrocarbon Mixtures in SaturatedUnsaturated Heterogeneous Media. Report LBNL-49375 Lawrence Berkeley National Laboratory. https://escholarship.org/uc/item/73m7d7c4.

Rasmusson, K., Rasmusson, M., 2009. NAPL Spill Modeling and Simulation of Pumping Remediation. M.S. Thesis. Uppsala Univ., Uppsala, Sweden.

Revil, A., Karaoulis, M., Johnson, T., Kemna, A., 2012. Review: Some low-frequency electrical methods for subsurface characterization and monitoring in hydrogeology. Hydrogeol. J. 20, 617-658. https://doi.org/10.1007/s10040-011-0819-x.

Revil, A., Skold, M., Karaoulis, M., et al., 2013. Hydrogeophysical investigations of the former S-3 ponds contaminant plumes, Oak Ridge Integrated Field Research Challenge site, Tennessee. Geophysics 78 (4), EN29-EN41. https://doi.org/10.1190/ geo2012-0177.1.

Robert, T., Martel, R., Lefebvre, R., Lauzon, J., Morin, A., 2017. Impact of heterogeneous properties of soil and LNAPL on surfactant-enhanced capillary desaturation. J. Contam. Hydrol. 204, 57-65. https://doi.org/10.1016/j.jconhyd.2017.07.006.

Ron, E.Z., Rosenberg, E., 2001. Natural roles of biosurfactants. Environ. Microbiol. 3, 229-236. https://doi.org/10.1046/j.1462-2920.2001.00190.x.

Rothmel, R.K., Peters, R.W., St. Martin, E., DeFlaun, M.F., 1998. Surfactant foam/ bioaugmentation technology for in situ treatment of TCE-DNAPLs. Environ. Sci. Technol. 32 (11), 1667-1675. https://doi.org/10.1021/es970980w.

Schroth, M.H., Istok, J.D., Ahearn, S.J., Selker, J.S., 1996. Characterization of Millersimilar silica sands for laboratory hydrologic studies. Soil Sci. Soc. Am. J. 60, 1331-1339. https://doi.org/10.2136/sssaj1996.03615995006000050007x.

Seferou, P., Soupios, P., Kourgialas, N.N., Dokou, Z., Karatzas, G.P., Candasayar, E., Papadopoulos, N., Dimitriou, V., Sarris, A., Sauter, M., 2013. Olive-oil mill wastewater transport under unsaturated and saturated laboratory conditions using the geoelectrical resistivity tomography method and the FEFLOW model. Hydrogeol. J. 
21, 1219-1234. https://doi.org/10.1007/s10040-013-0996-x.

Simyrdanis, K., Tsourlos, P., Soupios, P., Tsokas, G., Kim, J.H., Papadopoulos, N., 2015. Surface-to-tunnel electrical resistance tomography measurements. Near Surf. Geophys. 13, 343-354. https://doi.org/10.3997/1873-0604.2015019.

Slater, L., Binley, A., Versteeg, R., Cassiani, G., Birken, R., Sandberg, S., 2002. A 3D ERT study of solute transport in a large experimental tank. J. Appl. Geophys. 49, 211-229. https://doi.org/10.1016/S0926-9851(02)00124-6.

Soga, K., 2004. A review of NAPL source zone remediation efficiency and the mass flux approach. J. Hazard. Mater. 110, 13-27. https://doi.org/10.1016/j.jhazmat.2004.02. 034.

Steelman, C.M., Meyer, J.R., Parker, B.L., 2017. Multidimensional investigation of bedrock heterogeneity/unconformities at a DNAPL-impacted site. Groundwater 55, 532-549. https://doi.org/10.1111/gwat.12514.

Stone, H.L., 1970. Probability model for estimating three-phase relative permeability. J. Pet. Technol. 22, 214-218. https://doi.org/10.2118/2116-PA.

Timothy, J.D., Linda, M.A, 2000. The influence of field-scale heterogeneity on the infiltration and entrapment of dense nonaqueous phase liquids in saturated formations. J. Contam. Hydrol. 42, 187-218. https://doi.org/10.1016/S0169-7722(99)00092-3.

Tran, A.P., Vanclooster, M., Zupanski, M., Lambot, S., 2014. Joint estimation of soil moisture profile and hydraulic parameters by ground-penetrating radar data assimilation with maximum likelihood ensemble filter. Water Resour. Res. 50 (4),
3131-3146. https://doi.org/10.1002/2013WR014583.

Tso, C.M., Kuras, O., Wilkinson, P.B., Uhlemann, S., Chambers, J.E., Meldrum, P.I., Graham, J., Sherlock, E.F., Binley, A., 2017. Improved characterisation and modelling of measurement errors in electrical resistivity tomography (ERT) surveys. J. Appl. Geophys. 2017 (146), 103-119. https://doi.org/10.1016/j.jappgeo.2017.09. 009.

Waxman, M.H., Smits, L.J.M., 1968. Electrical conductivities in oil-bearing shaly sands. Soc. Petr. Eng. J 8, 107-122. https://doi.org/10.2118/1863-A.

Wen, X.H., Chen, W.H., 2005. Real-time reservoir model updating using ensemble Kalman filter. Spe. J. 11, 431-442. https://doi.org/10.2118/92991-MS.

Wilkins, M.D., Abriola, L.M., Pennell, K.D., 1995. An experimental investigation of Ratelimited nonaqueous phase liquid volatilization in unsaturated porous media: steady state mass transfer. Water Resour. Res. 31, 2159-2172. https://doi.org/10.1029/ 95WR01677.

Zheng, F., Gao, Y., Sun, Y., Shi, X., Xu, H., Wu, J., 2015. Influence of flow velocity and spatial heterogeneity on DNAPL migration in porous media: insights from laboratory experiments and numerical modelling. Hydrogeol. J. 23, 1703-1718. https://doi. org/10.1007/s10040-015-1314-6.

Zhou, J., Revil, A., Karaoulis, M., Hale, D., Doetsch, J., Cuttler, S., 2014. Image-guided inversion of electrical resistivity data. Geophys. J. Int. 197, 292-309. https://doi.org/ 10.1093/gji/ggu001. 